\title{
OD Modelling: a Promising Means for After-treatment Issues in Modern Automotive Applications
}

\author{
G. Mauviot", F. Le Berr, S. Raux, F. Perretti, L.M. Malbec and C.N. Millet \\ Institut français du pétrole, IFP, Direction Techniques d'Applications énergétiques, 1-4 avenue de Bois-Préau, \\ 92852 Rueil-Malmaison Cedex - France \\ e-mail: gilles.mauviot@ifp.fr - fabrice.le-berr@ifp.fr - stephane.raux@ifp.fr - florian.perrett@ifp.fr \\ lovis-marie.malbec@ifp.fr - claire-noelle.millet@ifp.fr \\ * Corresponding author
}

\begin{abstract}
Résumé - La simulation 0D : une voie d'avenir pour traiter les problématiques de post-traitement des véhicules automobiles modernes - Dans les véhicules automobiles modernes, les systèmes de post-traitement deviennent incontournables pour respecter les nouvelles normes de pollution. De ce fait, les problématiques autour du post-traitement deviennent de plus en plus significatives sur le coût de développement des moteurs et des véhicules. À titre d'exemple, certains scenarii montrent que le système de post-traitement d'un véhicule Diesel Euro 6 pourrait être composé de 5 éléments différents. Cette architecture complexe implique le développement d'outils sophistiqués pour aider à la conception de la ligne de post-traitement et à la définition de stratégies de contrôle. Ce papier démontre que la simulation zéro-dimension (0D) peut être une approche pertinente pour développer des simulateurs d'organes de post-traitement compatibles avec les exigences de précision et de temps de calculs demandées. Un modèle de monolithe original zéro-dimension est également décrit. L'approche est basée sur des éléments résistifs et capacitifs comme définis dans la théorie bond-graph [Karnopp D.C., Margolis D.L., Rosenberg R.C. (1990) Systems dynamics: a unified approach, Second Edition, John Wiley \& Sons, New-York]. Le modèle proposé prend en compte le comportement dynamique du fluide et le comportement thermique du monolithe. Plusieurs modèles de catalyseurs sont construits en associant ce modèle de monolithe avec des schémas réactionnels simplifiés tirés de la littérature [Koltsakis G.C., Konstandinis P.A., Stamatelos A.M. (1997) Development and application range of mathematical models for 3-way catalytic converters, Appl. Catal. B: Environ. 12, 161-191]. Diviser un modèle de monolithe en plusieurs blocs 0D élémentaires associés en série permet d'obtenir une bonne représentation de la dynamique présente à l'intérieur d'un catalyseur et d'accéder à des informations locales comme dans les modèles 1D avec des temps de calcul réduits [Depcik C., Assanis D. (2003) One-dimensional automotive catalyst modeling, Prog. Energ. Combust. 31, 308-369]. Cette approche peut être utilisée comme un moyen de compréhension de phénomènes complexes qui régissent le catalyseur impliquant plusieurs domaines de la physique. Elle représente aussi un outil de simulation pertinent dans la définition des architectures de ligne de post-traitement et dans le contrôle des émissions polluantes. Le potentiel de l'approche pour traiter l'ensemble des organes de post-traitement est illustré par des résultats sur un catalyseur trois voies (3WC), un catalyseur d'oxydation Diesel (DOC), un piège à NOx (LNT), un système de catalyse sélective des NOx (SCR) et un filtre à particules (DPF). Cette capacité à fournir avec un bon compromis temps/précision des informations intéressantes pour aider au développement de systèmes de post-traitement de plus en plus complexes rend la simulation 0D particulièrement attractive.
\end{abstract}




\begin{abstract}
D Modelling: a Promising Means for After-treatment Issues in Modern Automotive Applications - For modern automotive applications, after-treatment systems have become essential to respect the new emission standards. All the automotive world's attention is focused on catalysis systems because they seem to be one of the best ways to reach the future standards. As a result, after-treatment issues are more and more significant in the cost of the whole engine and vehicle development process. For example, the Euro 6 Diesel after-treatment line might for some applications be composed of nothing less than five distinct after-treatment bricks. This complex architecture implies developing advanced tools to help the exhaust line conception and also the design of associated control strategies. The present paper demonstrates that zero-dimensional (OD) simulation can be a relevant approach to develop exhaust line simulators compatible with accuracy and CPU time required performances. This paper proposes an original zero-dimensional model of the monolith. This approach is based on resistive and capacitive elements according to the bond graph theory [Karnopp D.C., Margolis D.L., Rosenberg R.C. (1990) Systems dynamics: a unified approach, Second Edition, John Wiley \& Sons, New-York]. The described dynamic model takes into account the pneumatic flow and the thermal behaviour of the monolith. Models of several catalysts are built by plugging this monolith model with some well-known simplified chemical reaction schemes [Koltsakis G.C., Konstandinis P.A., Stamatelos A.M. (1997) Development and application range of mathematical models for 3-way catalytic converters, Appl. Catal. B: Environ. 12, 161-191]. Splitting a monolith model into several elementary zero-dimensional blocks in series allows having a good representation of the specific internal dynamic of one catalyst and to access some local information as in conventional well-known one-dimensional models with low CPU time cost [Koltsakis G.C., Konstandinis P.A., Stamatelos A.M. (1997) Development and application range of mathematical models for 3-way catalytic converters, Appl. Catal. B: Environ. 12, 161-191]. Such an approach can be used as a way to get a phenomenological understanding of the catalytic system, which is known to be a very complex multi-physical system. It also represents a relevant simulation tool for the definition of after-treatment line architecture and pollutant emission control. The approach's potential to deal with all modern after-treatment bodies is illustrated by results for a Three-Way Catalyst (3WC), a Diesel Oxidation Catalyst (DOC), a Lean NOx Trap (LNT) system, a Selective Catalyst Reduction of NOx (SCR) system and a Diesel Particulate Filter (DPF). This ability to give, with a good compromise between accuracy/low CPU time cost, some interesting information to help the development of more and more complex exhaust system makes zero-dimensional simulation relevant.
\end{abstract}

\section{ABBREVIATIONS}

OD

Zero-Dimensional

1D One-Dimensional

3D Three-Dimensional

3WC Three-Way Catalyst

CPU Central Processing Unit

cpsi Cells per square inch

DOC Diesel Oxidation Catalyst

DPF Diesel Particulate Filter

GSHV Gas Space Hourly Velocity

FAER Fuel - Air Equivalent Ratio

FTIR Fourier Transform Infrared Spectroscopy

FTUV Fourier Transform UltraViolet

HC HydroCarbons

IMEP Indicated Mean Effective Pressure (bar)

LNT Lean NOx Trap

NEDC New European Driving Cycle

ppm Parts per million
RPM Revolutions Per Minute

SCR Selective Catalytic Reduction

SI Spark Ignition

SGTB Synthetic Gas Test Bench

\section{LIST OF SYMBOLS}

c Molar concentration of gases

$C_{g, i} \quad$ Molar concentration of gas \#i

$C p \quad$ Specific heat

$\mathrm{Ga}$ Density of external surface area in monolith

$h \quad$ Convective exchange coefficient

$h s \quad$ Specific enthalpy

$k_{c} \quad$ Mass transfer coefficient

$k_{h} \quad$ Heat transfer coefficient

$m \quad$ Mass

M Molar mass

$n \quad$ Number of mole

$P \quad$ Pressure 


$\begin{array}{ll}r & \text { Perfect gas constant } \\ R_{j} & \text { Reaction rate } \\ S & \text { Surface } \\ T & \text { Temperature } \\ u & \text { Local velocity } \\ V & \text { Volume } \\ y & \text { Molar fraction }\end{array}$

\section{GREEK SYMBOLS}

$\begin{array}{ll}\rho & \text { Density } \\ \rho_{a p p} & \text { Apparent density } \\ \varepsilon_{g} & \text { Void fraction } \\ \varepsilon_{S} & \text { Porosity of catalytic washcoat layer } \\ \varphi_{S} & \text { Volume fraction of catalytic washcoat in entire solid } \\ & \text { phase } \\ \lambda & \text { Heat conductivity } \\ \gamma & \text { Isentropic coefficient } \\ \psi_{m} & \text { Relative surface concentration of stored component } \\ \Omega_{m} & \text { Storage capacity } \\ \tau_{r} & \text { Residence time } \\ \tau_{c i} & \text { Chemical characteristic time } \\ \tau_{t h} & \text { Thermal characteristic time } \\ \tau_{t} & \text { Transport characteristic time } \\ v_{i j} & \text { Stoichiometric coefficients } \\ \omega & \text { Mass reaction rate }\end{array}$

\section{SUBSCRIPTS}

$\begin{array}{ll}c & \text { Catalyst } \\ \text { cha } & \text { Channel } \\ g & \text { Bulk gas } \\ i & \text { Species } \\ j & \text { Reaction } \\ m & \text { Monolith } \\ S & \text { Solid/gas interface }\end{array}$

\section{SUPERSCRIPTS}
in Inlet flow
out Outlet flow

\section{INTRODUCTION}

For modern automotive applications, after-treatment systems have become essential to respect the new emission standards. All the automotive world's attention is focused on catalysis systems because they seem to be one of the best ways to reach the future standards. As a result, after-treatment issues are more and more significant in the cost of the whole engine and vehicle development process. For example, the Euro 6 Diesel after-treatment line might for some applications be composed of nothing less than five distinct after-treatment bricks. This complex architecture implies developing advanced tools to help the exhaust line conception and also the design of associated control strategies. The present paper demonstrates that zero-dimensional (OD) simulation can be a relevant approach to develop exhaust line simulators compatible with accuracy and CPU time required performances. This paper proposes an original zero-dimensional model of monolith. This approach is based on resistive and capacitive elements according to the bond graph theory [1]. The described dynamic model takes into account the pneumatic flow and the thermal behaviour of the monolith. Models of several catalysts are built by plugging this monolith model with some well-known simplified chemical reaction schemes [2]. Splitting a monolith model into several elementary zerodimensional blocks in series allows having a good representation of the specific internal dynamic of one catalyst and to access some local information as in conventional well-known one-dimensional models [3] with low CPU time cost. Such an approach can be used as a way to get a phenomenological understanding of the catalytic system, which is known to be $a$ very complex multi-physical system. It also represents a relevant simulation tool for the definition of after-treatment line architecture and pollutant emission control. The approach's potential to deal with all modern after-treatment bodies is illustrated by results for a Three-Way Catalyst (3WC), a Diesel Oxidation Catalyst (DOC), a Lean NOx Trap (LNT) system, a Selective Catalyst Reduction of NOx (SCR) system and a Diesel Particulate Filter (DPF). This ability to give, with a good compromise between accuracy/low CPU time cost, some interesting information to help the development of more and more complex exhaust systems makes zero-dimensional simulation relevant.

\section{OVERVIEW OF THE AFTER-TREATMENT ISSUES}

For a long time now, emission regulations for mobile sources have no longer been satisfied by only improving the combustion process. In the early nineties, three-way catalytic (3WC) after-treatment devices became mandatory for gasoline fuelled vehicles in Europe. A few years later, oxidation catalysts (DOC) were introduced at the exhaust of Diesel-powered vehicles. More recently, in 2000, PSA Peugeot-Citroën launched what is becoming a standard for Diesel engines, the combination of a DOC and a particulate filter (DPF) to remove soot from the exhaust gases. NOx after-treatment systems, which only a few car manufacturers have already implemented on serial applications, are awaited for the upcoming years. 


\subsection{After-treatment Motivations}

Transport is one of the major contributors to the pollutant concentration in the air. Catalytic converters allow the reduction of pollutant emissions down to a level that only combustion optimisation alone does not permit for the moment. Through these disposals, Diesel particulate emissions were divided by ten between the Euro 3 regulation (2000) and Euro 5 regulation (2009), while nitrogen oxides will be cut by about six with the Euro 6 regulation (2014) compared with the Euro 3 regulation (Fig. 1). Meanwhile, gasoline engine emissions have been more than halved. The remaining emissions are much harder to reduce, which has led to continuing research on after-treatment systems, control strategies to manage them and new tools to help development.

\subsection{The Different After-treatment Systems}

Gasoline engines have made significant progress in reducing their pollutant emissions by adopting the so-called three-way catalysis. This kind of catalytic converter simultaneously oxidises unburned hydrocarbons and carbon monoxide, and reduces nitrogen oxides. This technology has been continuously improved in order to confer faster light-off and increased durability, while involving ever less precious metals.

Diesel engines were firstly only equipped with oxidation catalysts, waiting for technologies dealing with particles and NOx. In 2000, for the Euro 3 regulation, PSA was the first car manufacturer in the world to produce a vehicle equipped with a particulate filter. Nine years later, with the upcoming

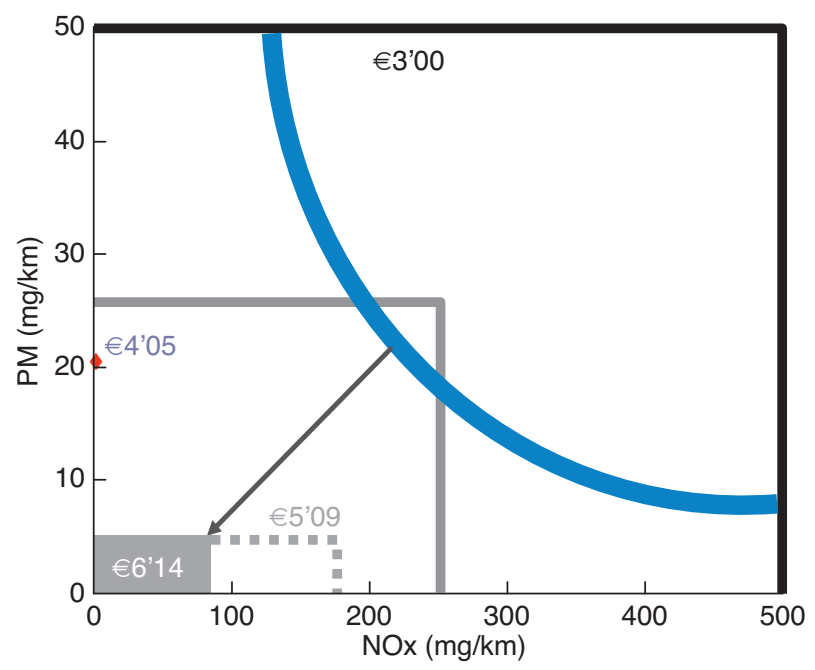

Figure 1

Pollutant emission standard evolution between Euro 3 and Euro 6 concerning NOx and particles (PM) for Diesel vehicle applications.
Euro 5 regulation, DPFs are about to be implemented in all Diesel-powered vehicles. A catalyst is required to lower the combustion temperature of trapped soot. This catalyst can either be an oxide (rare earth or iron) added to the fuel or a precious metal (most of the time platinum) deposited on DPF walls. In both cases, a DOC is required in front of the DPF in order to elevate the temperature by oxidising $\mathrm{HC}$ and $\mathrm{CO}$ from exhaust gases.

The future Euro 6 regulation will probably urge manufacturers to implement a NOx after-treatment device to comply with an emission target as low as $80 \mathrm{mg} / \mathrm{km}$ (Fig. 1). Two technologies are expected to reach this level: lean NOx trap (LNT) and selective catalyst reduction (SCR) systems. The first one traps nitrogen oxides on a basic oxide (mainly barium oxide) and releases trapped NOx in order to reduce them to nitrogen in the presence of reducing species through periodical stoichiometric engine operating conditions. The second one consists of introducing some urea into exhaust gases, which breaks up into ammonia to continuously reduce the NOx.

LNT devices involve a large amount of precious metal which makes them expensive, even if the latest developments show that rhodium, the most expensive one, could no longer be required [4]. SCR systems, based on zeolites, are much cheaper as they do not require precious metal. Nevertheless, the whole system cost is rather high due to the need for specific devices such as a tank for urea solution (called AdBlue $\left.^{\mathrm{TM}}\right)$, a pump to pressurise the fluid and an injector.

Moreover, LNT systems are poisoned by sulphur contained in fuel and lubricant, while SCR devices may be clogged by melamine complexes if the system does not run properly. Both systems have the same weak point: a low efficiency at low temperatures. At temperatures below $150-180^{\circ} \mathrm{C}$, for SCR systems, urea cannot be efficiently decomposed into ammonia, which leads to poor conversions and undesirable species to be created. Meanwhile, LNT cannot efficiently store nitrogen oxides, and cannot be regenerated in such cold conditions. Thus, temperature is the key factor to perform the targeted efficiency on the European Driving Cycle.

\subsection{Experimental Setup for After-treatment Characterisation}

The engine test bench and synthetic gas test bench (SGTB) are the two experimental means used to characterise the after-treatment devices and optimise their interactions with the engine. Each after-treatment system has specific needs concerning analysis setup linked to the diagnoses' expected accuracy. For instance, SCR systems may only be characterised using NOx and ammonia analysers or sensors. However; mass spectrometry appears useful to characterise the efficiency of the thermolysis reaction to break up urea into isocyanic acid and ammoniac entering the SCR. 
As LNT catalysts are poisoned by sulphate from sulphur contained in fuel and lubricant, their accurate characterisation requires specific analysis of $\mathrm{SO}_{2}, \mathrm{H}_{2} \mathrm{~S}$ and $\mathrm{COS}$ during the desulphation phases to measure their efficiency. Mass spectrometry is again involved here, but FTIR or FTUV analysers may provide partial but useful information. Furthermore, optimising the LNT deNOx efficiency means minimising the NOx slip during short, rich purges (less than 5 seconds). Analysers using chemiluminescence detectors located as close as possible to the sampling point give a very fast answer with a resolution time of about a few milliseconds.

These characterisations can be carried out either on the engine test bench, which is very representative of the conditions encountered in a vehicle, or on a SGTB that allows one to study separately reactions taking place in the catalyst to improve their understanding.

The data provided by these experimental means allow understanding of the system but also improve model calibration.

\subsection{A Complex System...}

As described above, NOx after-treatment devices developed for the Euro 6 emission regulation are much more complex than simple oxidation or even three-way catalysts because they need a specific management of the engine or the use of additional injection devices. LNT purges by rich combustion have to be managed accurately to optimise efficiency and limit fuel consumption. Control of SCR systems and associated urea injection aims to optimise NOx reduction efficiency while limiting $\mathrm{NH}_{3}$ slip at the catalyst outlet. Control strategies thus have to deal with NOx reduction depending on temperature, $\mathrm{NH}_{3}$ concentration and exhaust gas composition (fraction of $\mathrm{NO}_{2}$ in $\mathrm{NOx}$ ), but also with $\mathrm{NH}_{3}$ storage in the catalyst, that strongly depends on temperature.

The same kind of statement also applies to the regeneration of a particulate filter. Periodically, at a frequency depending on the mass of soot trapped in the DPF, a rise of the filter inlet temperature is generated in order to burn soot. This temperature has to be high enough to burn soot as quickly as possible for consumption purposes, but not too high to prevent any destructive temperature overshoot. The targeted temperature can be obtained by two means that can be combined: delaying the combustion in the cylinder to increase exhaust temperature or adding reducing species to exhaust gases with a late post-injection or with an exhaust port injector (EPI). Reducing species will be oxidised on a DOC located upstream of the DPF which will increase the DPF inlet temperature.

To reduce the cost and time duration of after-treatment system control development, simulation tools are relevant. They offer the possibility to access a virtual system to design and validate control strategies but also to access non-measurable variables to create observers for open-loop strategy definition, a challenge as far as the very small tolerances around the targeted values are concerned.

\section{MODELLING IN AFTER-TREATMENT}

\subsection{State of the Art}

Models for after-treatment purposes can be divided into 3 categories:

- simplified models dedicated to simulators for control purposes;

- 1D models used to design the after-treatment line and to test industrial solutions;

- 2D and 3D models used to study complex phenomena inside the different exhaust line devices.

\subsubsection{Models Used for Control Purposes}

In this first category, the most important requirement is CPU time performances of after-treatment models. In fact, control engineers need simulators including a complete exhaust line in some cases associated with an engine simulator in order to develop their control strategies; particulate filter or lean NOx trap regeneration, for instance. These simulators also have the ability to operate at real time. In order to reach these objectives, a lot of models have been proposed in the literature concerning all components of a modern exhaust line [5].

\subsubsection{One-dimensional Models}

Nowadays, designing an exhaust line associated with a modern engine has become more and more expensive with the diversity of solutions proposed for after-treatment purposes. In this context, numerical tools are very useful to help engineers to select the best configuration while minimising development cost. To perform this work, one-dimensional (1D) models seem to be the most relevant tools because they propose the best compromise between physical modelling capability, CPU time cost and user's agreement. Several software environments offer one- dimensional solutions in order to model exhaust systems such as AVL BOOST [8], GASDYN [9] and GT-POWER [10]. [3] propose a large review of existing one-dimensional automotive catalyst models and their evolution. They are usually built from the same structure (monolith model). The monolith is divided into three phases: the bulk gas, the reactive surface and the solid phase.

A model of the monolith is described below to illustrate a classical 1D approach. It is extracted from a software environment called ExACT used at Daimler AG [11]. The bulk gas temperature and the bulk gas species equations are written as follows:

$$
\rho_{g} C p_{g} \frac{\partial T_{g}}{\partial t}+\rho_{g} C p_{g} u \frac{\partial T_{g}}{\partial x}=\frac{k_{h} G a}{\varepsilon_{g}}\left(T_{m}-T_{g}\right)
$$




$$
\frac{\partial C_{g, i}}{\partial t}+\frac{\partial\left(C_{g, i}\right)}{\partial x}=\frac{k_{m, i} G a}{\varepsilon_{g}} c\left(y_{S, i}-y_{g, i}\right)
$$

with $G a$, density of external surface area in monolith; $\varepsilon_{g}$, void fraction; $y$, molar fraction; $c$, molar concentration of gas; $C_{g, i}$, molar concentration of the species $\# i ; k_{m, i}$, corresponding transport coefficient.

At the solid/gas interface, mass and energy balances are solved:

$$
\begin{aligned}
& \rho_{S} C p_{S} \frac{\partial T_{S}}{\partial t}=\lambda \frac{\partial^{2} T_{S}}{\partial x^{2}}+\frac{k_{h} G a}{1-\varepsilon_{g}}\left(T_{g}-T_{S}\right)-W\left(T_{S}-T_{e x t}\right) \\
& -\varphi_{S} \sum_{j=1}^{J} \Delta H_{r, j} R_{j} \\
& \frac{\partial C_{S, i}}{\partial t}=\frac{k_{c} G a}{\varepsilon_{S}\left(1-\varepsilon_{g}\right) \phi_{S}} c\left(y_{g, i}-y_{S, i}\right)+\frac{1}{\varepsilon_{S}} \cdot \sum_{j=1}^{J} v_{i, j} R_{j}
\end{aligned}
$$

with $\lambda$ designates heat conductivity; $v_{i j}$, stoichiometric coefficients; $k_{c}$, mass transfer coefficient; $k_{h}$, heat transfer coefficient; $\varepsilon_{s}$, porosity of catalytic washcoat layer; $\phi_{s}$, volume fraction of catalytic washcoat in entire solid phase; $R_{j}$, reaction rate.

Finally, a mass balance on the catalyst surface is computed:

$$
\frac{\partial \psi_{m}}{\partial t}=\frac{1}{\Omega_{m}} \sum_{j=1}^{J} v_{m, j} R_{j}
$$

with $\psi_{m}$ designates relative surface concentration of stored component and $\Omega_{m}$ storage capacity.

\subsubsection{Three-dimensional Models}

The last category of models concerns 2D and 3D CFD models. They are usually developed in order to optimise catalysts geometry, exhaust pipe structure and injector flow properties. Nowadays, there are commonly used in Diesel particulate filter [12] and Selective Catalytic Reduction [15] applications. This kind of model is used to deal with heterogeneity issues inside the exhaust line, to optimise fuel or urea injected before entering the DPF or SCR devices or to locate reactions inside the after-treatment bodies. As with all multidimensional level models, CPU time makes them usable only for design aspects and most of the time only a small part of the exhaust line is simulated.

\subsection{IFP-EXHAUST Library}

The IFP-EXHAUST library (Fig. 2) has been developed in the LMS.IMAGINE.Lab environment. This library is composed of several elementary components allowing the reproduction of most of the existing modern exhaust lines. This library includes pipes with several geometries, volumes, elements to simulate thermal transfers, sensors, pressure and mass flow sources, several kinds of catalysts (LNT, DOC, $3 \mathrm{WC}$ and SCR), and DPF.

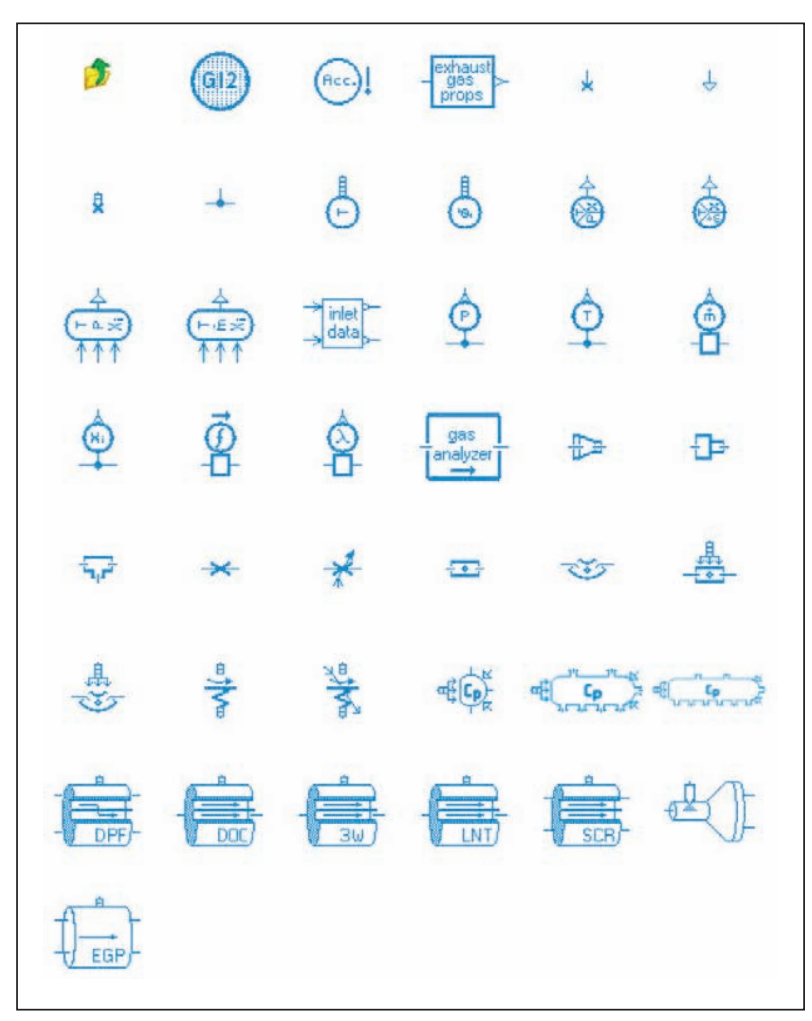

Figure 2

Composition of the IFP-EXHAUST library.

The 0D approach proposed in the IFP-EXHAUST library has been developed in order to reach the best compromise between CPU performances and physical accuracy modelling. The OD approach objective is to use the same platform and the same models to make simulators for both control design issues and exhaust line conception issues.

To reach these objectives, models are developed from quite complex structures close to those used in 1D models (described in the previous part) keeping the numerical advantage of a classical zero-dimensional approach in order to minimise CPU time cost.

\section{OD MODELLING BASICS}

\subsection{A Complex Physical System}

A catalyst could be first defined as a simple reactor with several chemical functions to represent mainly pollutant conversions. However, a catalyst inside an after-treatment line is a very complex system. To fully understand how this system operates, it is necessary to consider all the physical processes inside the catalyst, and not only the chemical 
scheme. One way to describe the catalyst and to model it in a simple way consists of listing the main physical characteristic times defining such a system.

First, a residence time $\left(\tau_{t}\right)$ must be mentioned. This time is defined from the open volume of the catalyst $\left(V_{g}\right)$, the mass flow rate of exhaust gases $\left(\dot{m}_{g}\right)$ and the corresponding density $\left(\rho_{g}\right)$ :

$$
\tau_{r}=\frac{\rho_{g} \cdot V_{g}}{\dot{m}_{g}}
$$

A chemical time $\left(\tau_{c i}\right)$ is associated with the main catalytic reaction rate of species $\# i\left(\dot{\omega}_{c i}\right)$ and its corresponding concentration $\left(C_{i}\right)$ :

$$
\tau_{c i}=\frac{M_{i} \cdot C_{i}}{\dot{\omega}_{c, i}}
$$

A thermal characteristic time $\left(\tau_{t h}\right)$ defines the thermal behaviour of the monolith. It is defined from the monolith's apparent density $\left(\rho_{a p p}\right)$, its specific heat $\left(C p_{m}\right)$, the catalyst volume $\left(V_{c}\right)$, the exterior surface of the monolith $\left(S_{\text {ext }}\right)$, and its corresponding convective exchange coefficient $\left(h_{e x t}\right)$ :

$$
\tau_{t h}=\frac{\rho_{a p p} \cdot V_{c} \cdot C p_{m}}{h_{e x t} \cdot S_{e x t}}
$$

Finally, it is necessary to consider a transport time $\left(\tau_{t}\right)$ to take into account the time for a molecule to reach a catalytic site. This characteristic time depends on a transport coefficient associated with species $\# i\left(k_{i}\right.$ and a characteristic length corresponding to the diameter of one channel $\left(d_{c}\right)$ :

$$
\tau_{t}=\frac{d_{c}}{k_{i}}
$$

This list of characteristic times is limited. In fact, a lot of existing phenomena are not taken into account. This list could be widely extended to include specific mass transfer inside the washcoat, for example. Nevertheless, the objective is to take into account only the main axes of an operating catalyst in order to set up a very simple model approach. As illustrated in the next parts, such an approach allows reproducing physical tendencies in several concrete applications.

In the following parts, the modelling approach and main assumptions will be discussed.

\subsection{Bond Graph Approach [1]}

The modelling approach presented in this paper is based on the bond graph theory [1]. In such an approach, multi-physical systems such as catalysts catalyst are modelled with association of capacitive elements (volume), resistive elements (pressure drop) and eventually inertia elements. The main assumption in the catalyst modelling is to consider only one channel representative of the whole monolith. Figure 3 presents the model of a flow stream inside the channel in bond

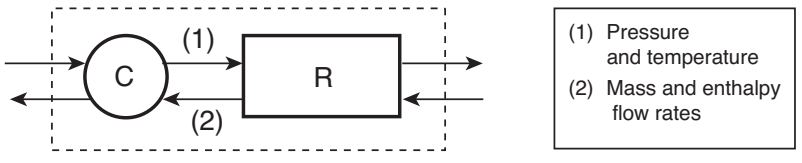

Figure 3

Basic model of a flow stream in one channel.

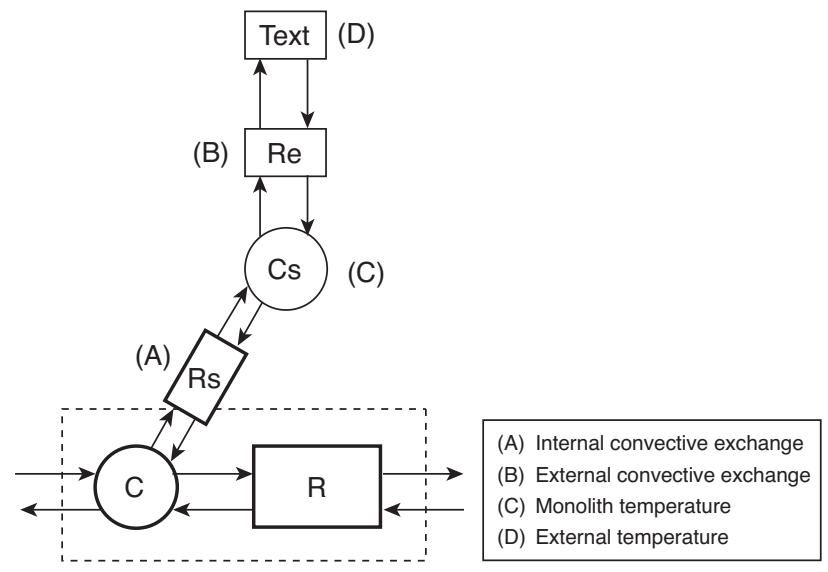

Figure 4

Model of one channel including monolith with thermal aspects.

graph theory. It is composed of one capacitive element associated with one resistive element. The volume (capacitive element) is comparable with an open reactor where pressure and temperature are deduced from mass and energy balances, whereas the resistive element is used to compute mass and enthalpy flow rates through a channel from the well-known pressure drop law.

Figure 4 presents the complete bond graph model of a catalyst including the solid phase (monolith) and thermal transfers. The monolith is considered here as a thermal capacity $(C s)$ where a solid temperature is computed from an energy balance. This capacity is linked to the gaseous capacity $(C)$ with an internal convective exchange $(A)$. Finally, an external convective exchange $(B)$ between the monolith and ambient air $\left(T_{\text {ext }}\right)$ is computed.

Each model of catalyst is built with this general structure. The only difference consists in their specific catalysis functions. Catalytic reactions take place in the gaseous volume and affect the gaseous composition, whereas the resulting heat release is fully done in the solid capacity. This assumption is discussed in the next part.

One element of the IFP-EXHAUST library has specific bond graph causality. In fact, due to its original operating 


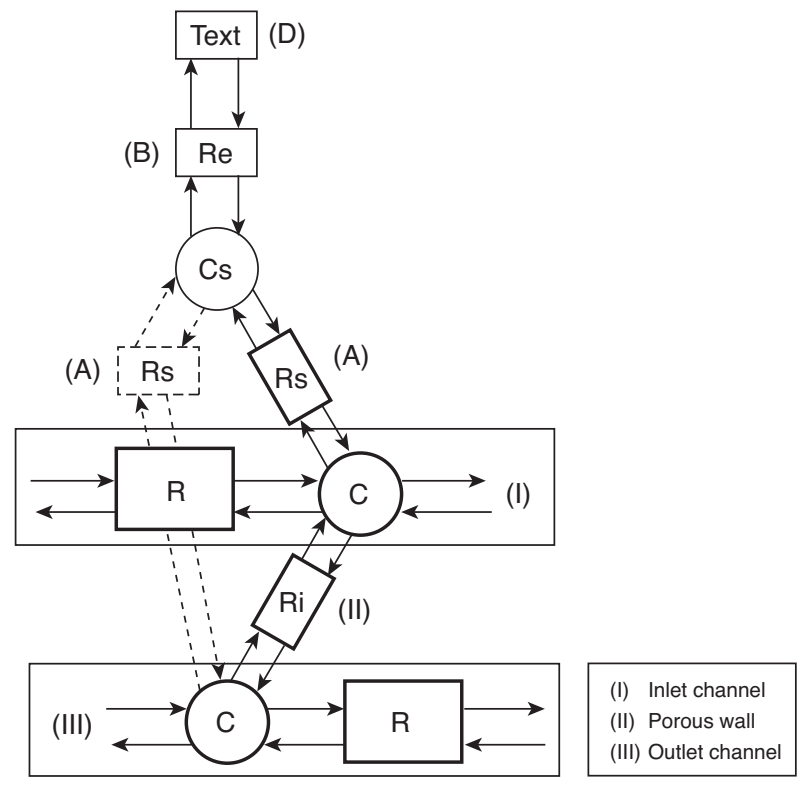

Figure 5

Basic structure of a DPF element.

conditions, the Diesel Particulate Filter element is composed of a two-channel model. As shown in Figure 5, inlet and outlet channels are linked with a resistive element $(R i)$ modelling the mass flow rate through a porous wall.

All models described below are only composed of zerodimensional components but it is possible to associate several OD elements in series (Fig. 6) in order to represent some 1D phenomena such as the repartition of chemical activities through the monolith.

\subsection{General Equations}

\subsubsection{Bulk}

In a capacitive element of gas, the mass balance for species $i$ is computed as follows:

$$
\frac{d m_{g, i}}{d t}=\dot{m}_{g, i}^{i n}-\dot{m}_{g, i}^{\text {out }}+\dot{\omega}_{g, i}
$$

with $\dot{m}_{g, i}^{\text {in }}, \dot{m}_{g, i}^{\text {out }}$ designate, respectively the inlet and the outlet mass flow rate of the species $\# i$ in a volume and $\dot{\omega}_{g, i}$ the resulting reaction rate due to catalytic reactions.

The gaseous pressure $\left(P_{g}\right)$ is computed from an energy balance:

$$
\frac{d P_{g}}{d t}=\frac{\gamma \cdot P_{g}}{m_{g} C_{p} T_{g}}\left[\delta \dot{Q}_{t h, i n}+M_{g} C_{p} T_{g} \cdot \frac{d n_{g}}{d t}+\dot{m} \delta h\right]
$$

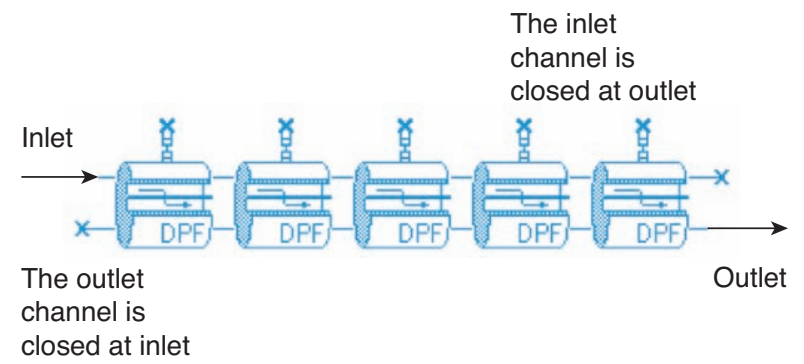

Figure 6

Example of multi-0D model of one DPF system composed of five basic elements.

with $\gamma$ designates the isentropic coefficient; $T_{g}$, the gas temperature; $C p_{g}$, the gas specific heat; $n_{g}$, the number of mole in the gas; $M_{g}$, the gas molar mass; $\delta \dot{Q}_{t h, i n}$, the internal heat transfer.

This term is computed with this equation:

$$
\delta \dot{Q}_{t h, i n}=h_{c o n v, i n} \cdot S_{r} \cdot\left(T_{s}-T_{g}\right)
$$

with $T_{s}$ designates the monolith temperature and $S_{r}$ the reactive surface.

The last term of Equation (11) corresponds to the impact of composition evolution inside the volume:

$$
\dot{m} \delta h=\sum_{i}\left[\left(h s_{i}^{i n}-h s_{i}\right) \cdot \dot{m}_{g, i}^{i n}-h s_{i} \dot{\omega}_{g, i}\right]
$$

$h s_{i}^{i n}, h s_{i}$ designate, respectively, the specific enthalpy of the income gas and the specific enthalpy of the gas inside the volume. Finally, the term $h s_{i} \dot{\omega}_{g, i}$ corresponds to the impact of catalytic reactions.

The gaseous temperature is deduced from perfect gas law:

$$
T_{g}=\frac{P_{g}}{\rho_{g} r_{g}}
$$

$\rho_{g}, r_{g}$ are, respectively, the gas density and the perfect gas constant.

In a resistive element, mass and enthalpy flow rates are computed from a classical Poiseuille law inside a square channel. They depend on the pressure drop $(\Delta P)$, the open surface $\left(S_{g}\right)$, the dynamic viscosity $(\mu)$, the upstream enthalpy $\left(h_{u p}\right)$, the channel diameter $\left(d_{c}\right)$ and the channel length $\left(L_{c}\right)$ :

$$
\begin{gathered}
\dot{m}_{g}=\rho_{g} \cdot S_{g} \cdot \frac{\Delta P \cdot d_{c}{ }^{2}}{32 \cdot \mu \cdot L_{c}} \\
d H_{g}=h s_{u p} \cdot \dot{m}_{g}
\end{gathered}
$$




\subsubsection{Monolith}

The monolith is modelled from a capacitive element. Thus, the monolith temperature $\left(T_{s}\right)$ is computed from an energy balance:

$$
\frac{d T_{s}}{d t}=\frac{\delta \dot{Q}_{t h, e x t}-\delta \dot{Q}_{t h, i n}+\delta \dot{Q}_{R E A C}}{\rho_{S} \cdot C p_{S}}
$$

with $\delta \dot{Q}_{t h, i n}$, corresponds to Equation (10). $\delta \dot{Q}_{t h, e x t}$, designates the external heat transfer:

$$
\delta \dot{Q}_{t h, e x t}=h_{c o n v, e x t} S_{e x t}\left(T_{e x t}-T_{g}\right)
$$

$\delta \dot{Q}_{R E A C}$, corresponds to the heat release due to catalytic reactions

\subsection{Main Assumptions}

In this part, main assumptions are discussed. The main objective is to underline the limitations of such an approach in order to set up the application field of the numerical tool previously described.

First, using a zero-dimensional approach implies having some general assumptions:

- the monolith is assimilated with only one mean channel.

This is the fundamental assumption of $0 D$ and 1D approaches in the literature. This property leads to neglecting radial heterogeneities of temperature and gas composition in the catalyst. This is a limitation to studying geometrical aspects of an after-treatment device. For this specific case, 3-dimensional modelling seems to be more adequate;

- to take into account one-dimensional axial phenomena, it is necessary to use a multi-0D model, as seen in Figure 6. For after-treatment devices, this approach is a good approximation of a one-dimensional model. In fact, using a multi-0D approach implies only two main additional assumptions in respect to the 1D model. First, axial diffusion of mass and energy is neglected. Given the high velocity of gases inside a catalyst (several metres per second), this assumption is not a restrictive one. The second assumption is that momentum balances are not solved in the multi-0D approach. As a result, pressure waves are not computed in such a model.

Some assumptions have been added in order to simplify the system and to reach some high CPU performances:

- the bulk flow composition is supposed to be the same as the surface composition. As a result, there is no specific dynamic associated with the mass transfer from bulk to the reactive sites. This transport process is directly linked to reaction rates introducing an equivalent Damkohler number $D a=\frac{\tau_{c}}{\tau_{t}}$. This assumption implies that processes concerning radial mass transport and diffusion of molecules inside the washcoat are not dissociated;
- the heat release due to catalysed reactions is assumed to be inside the solid phase (monolith). A part of this energy is transferred to the bulk flow thanks to the internal convective transfer with the monolith.

Finally, this OD modelling approach seems to be very relevant to deal with all modern after-treatment issues. As illustrations, different applications are treated in the following parts by showing results of a $3 \mathrm{WC}$, a DOC, a LNT system, a SCR device and a DPF.

\section{THREE-WAY CATALYST (3WC)}

The three-way catalyst (3WC) is the widespread solution for after-treatment on gasoline engines. Its performances in terms of emission conversions are excellent for the standard pollutants (CO, HC and NOx). Nevertheless, to reach these performances, the engine has to work as close to the stoichiometric fuel - air equivalent ratio (FAER) as possible. One of the main objectives of the control system is to manage the engine performances while keeping the FAER close to one to optimize pollutant conversion in the 3WCC when light-off temperature is reached. Nevertheless, because of transient engine operating conditions during driving cycles, FAER might take lean and rich values around the stoichiometric point. This is the reason why generally $3 \mathrm{WC}$ tests are performed between 0.98 and 1.02 of FAER.

To optimise the $3 \mathrm{WC}$ operation, modern catalysts (notably with ceria) have the particularity of enlarging the window of FAER with good efficiency. These performances are possible by activation of reactions involving water, particularly in rich conditions. When no oxidant species $\left(\mathrm{O}_{2}, \mathrm{NOx}\right)$ remain, water has the possibility of oxidising unburnt hydrocarbons and carbon monoxide.

In this context, a OD $3 \mathrm{WC}$ model was created and calibrated to represent the system behaviour for various FAER and Gas Space Hourly Velocities (GSHV). 3WC simulators were calibrated and validated with laboratory test results as presented in this part of the paper.

\subsection{Experimental Setup}

All measurements were carried out an engine test bench equipped with a 4-cylinder SI engine with a displacement of $2200 \mathrm{~cm}^{3}$. The catalytic converter used was a metallic monolith of $1.1 \mathrm{~L}$ with a density of $400 \mathrm{cpsi}$.

Tests consist of typical 3WC light-off experiments on two sets of steady-state operating conditions, described in Table 1. The objectives of these tests are notably the determination of the light-off temperature for $\mathrm{CO}, \mathrm{NOx}$ and $\mathrm{HC}$ (50\% conversion) for various equivalence ratios, and evolution of the pollutant conversions as a function of time and temperature. For both studied sets of operating conditions, 3 FAER were tested: $0.98,1$ and 1.02 . 
TABLE 1

Engine operating conditions description

\begin{tabular}{c|c|c|c|c}
\hline $\begin{array}{c}\text { Operating } \\
\text { conditions }\end{array}$ & $\begin{array}{c}\text { Engine } \\
\text { speed (rpm) }\end{array}$ & $\begin{array}{c}\text { BMEP } \\
(\mathrm{bar})\end{array}$ & $\begin{array}{c}\text { Total flow } \\
\text { rate }(\mathrm{kg} / \mathrm{h})\end{array}$ & $\begin{array}{c}\text { GSHV } \\
\left(\mathrm{h}^{-1}\right)\end{array}$ \\
\hline No. 1 & 1300 & 5.5 & 48 & 40000 \\
\hline No. 2 & 2000 & 5.5 & 83 & 70000 \\
\hline
\end{tabular}

Gas temperature and composition were measured upstream and downstream of the $3 \mathrm{WC}$. Analysed gases were total hydrocarbons $(\mathrm{HC}), \mathrm{CO}, \mathrm{NOx}, \mathrm{CO}_{2}$, and $\mathrm{O}_{2}$. As only one gas composition analyser was available during the study, gas composition measurement was performed two times: a first test for the upstream gas composition measurement and a second one for the downstream side. This measurement methodology explains the differences noticed in the results between upstream and downstream measurements when no conversion occurs (particularly for low temperatures).

\subsection{Reaction Scheme}

The reactions taken into account in the $3 \mathrm{WC}$ model are those presented in [16]. The hydrocarbon was written as $\mathrm{C}_{x} \mathrm{H}_{y}$.

- oxidation reactions:

$$
\begin{aligned}
\mathrm{CO}+\frac{1}{2} \mathrm{O}_{2} & \rightarrow \mathrm{CO}_{2} \\
\mathrm{C}_{x} \mathrm{H}_{y}+\left(x+\frac{y}{4}\right) \mathrm{O}_{2} & \rightarrow x \mathrm{CO}_{2}+\frac{y}{2} \mathrm{H}_{2} \mathrm{O} \\
\mathrm{H}_{2}+\frac{1}{2} \mathrm{O}_{2} & \rightarrow \mathrm{H}_{2} \mathrm{O}
\end{aligned}
$$

- NO reduction:

$$
\begin{aligned}
\mathrm{NO}+\mathrm{CO} & \rightarrow \frac{1}{2} \mathrm{~N}_{2}+\mathrm{CO}_{2} \\
\mathrm{NO}+\mathrm{H}_{2} & \rightarrow \frac{1}{2} \mathrm{~N}_{2}+\mathrm{H}_{2} \mathrm{O} \\
\mathrm{C}_{x} \mathrm{H}_{y}+\left(2 x+\frac{y}{2}\right) \mathrm{NO} & \rightarrow x \mathrm{CO}_{2}+\frac{y}{2} \mathrm{H}_{2} \mathrm{O}+\left(\frac{y}{4}+x\right) \mathrm{N}_{2}
\end{aligned}
$$

- water gas shift and steam reforming:

$$
\begin{gathered}
\mathrm{CO}+\mathrm{H}_{2} \mathrm{O} \rightleftarrows \mathrm{CO}_{2}+\mathrm{H}_{2} \\
\mathrm{C}_{x} \mathrm{H}_{y}+x \mathrm{H}_{2} \mathrm{O} \rightarrow x \mathrm{CO}+\frac{2 x+y}{2} \mathrm{H}_{2}
\end{gathered}
$$

To calibrate the parameters of these reactions, the methodology consisted of using the values presented in [16] (model calibrated on lab test results) and adjusting the different parameters to improve the results on the engine test bed configuration in the second step.

\subsection{Simulation Results}

The complete $3 \mathrm{WC}$ model is composed of $70 \mathrm{D}$ elements (Fig. 7) to account for temperature and gas composition evolution through the catalyst.

In this paper, 4 tests are presented with the following characteristics in terms of GSHV and FAER:

- $\mathrm{GSHV}=70000 \mathrm{~h}^{-1}, \mathrm{FAER}=0.98$

- $\mathrm{GSHV}=70000 \mathrm{~h}^{-1}, \mathrm{FAER}=1$

$-\mathrm{GSHV}=70000 \mathrm{~h}^{-1}, \mathrm{FAER}=1.02$

- GSHV $=40000 \mathrm{~h}^{-1}, \mathrm{FAER}=1$

For each set of operating conditions, pollutant emissions ( $\mathrm{CO}, \mathrm{HC}$ and $\mathrm{NOx}$ ) and temperature before and after the catalyst are presented.

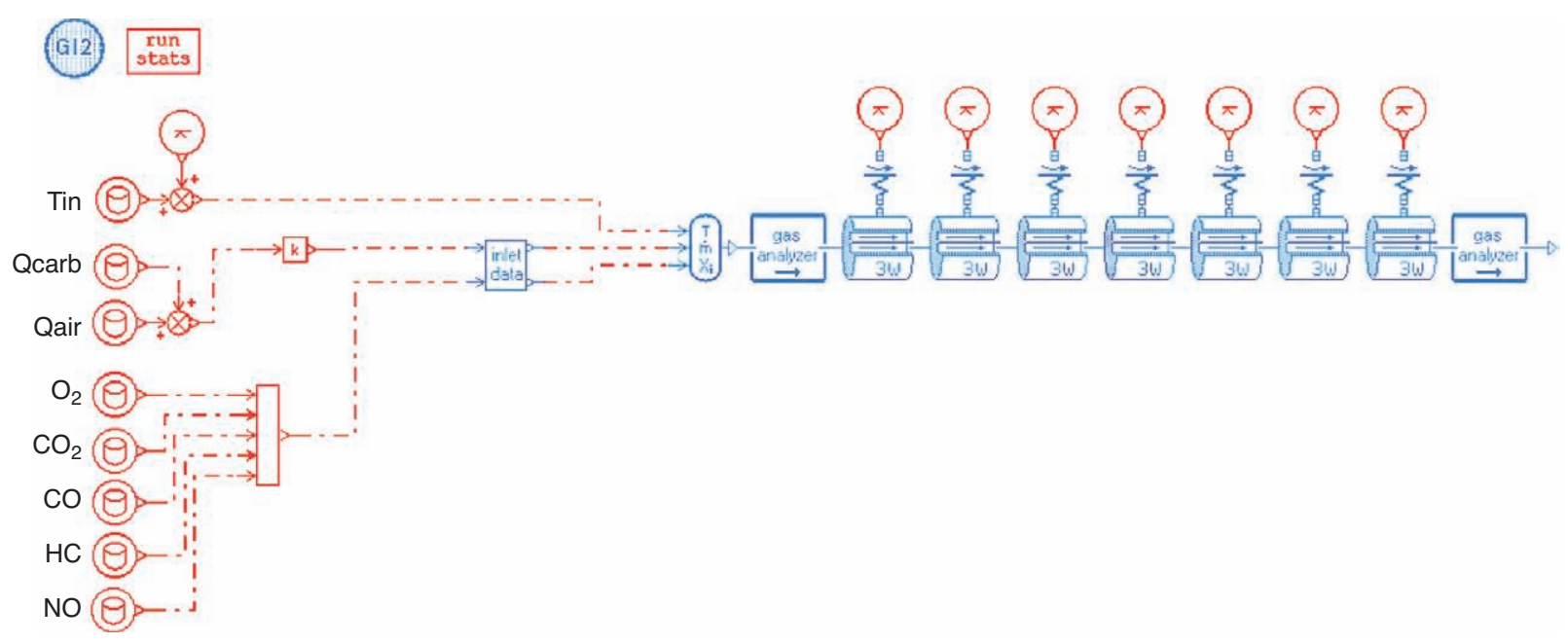

Figure 7

Sketch of the $3 \mathrm{WC}$ simulator. 

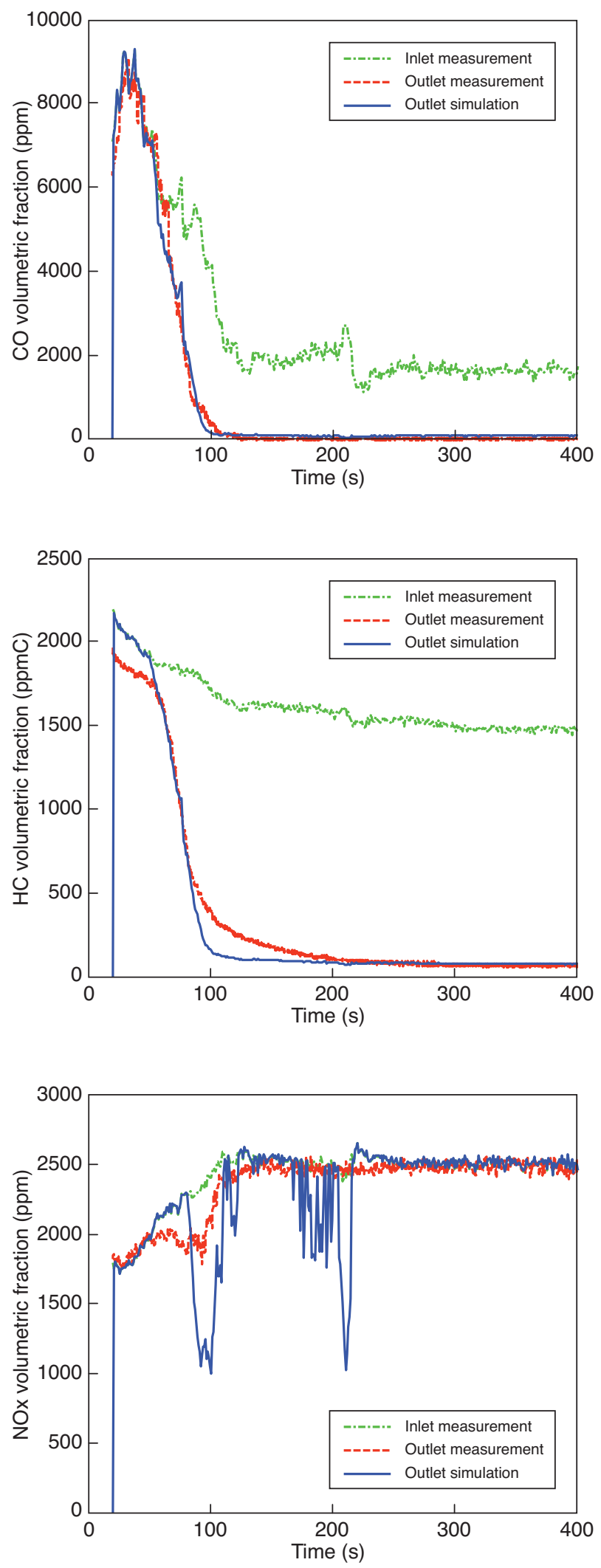

Figure 8

Comparison of pollutant conversion between experimental and simulation results @ GSHV $=70000 \mathrm{~h}^{-1}$ and FAER $=0.98$.

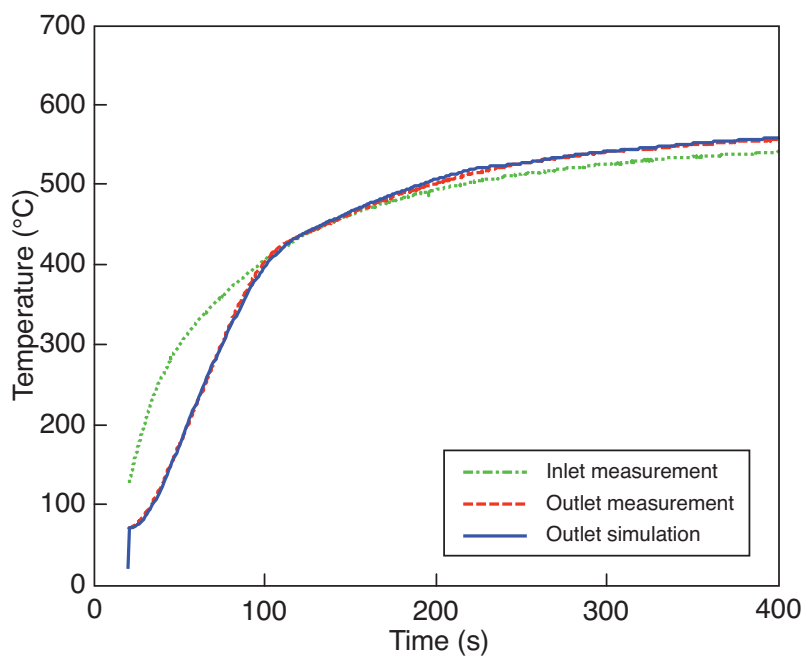

Figure 9

Comparison of temperature evolution between experimental and simulation results@ GSHV $=70000 \mathrm{~h}^{-1}$ and FAER $=0.98$.

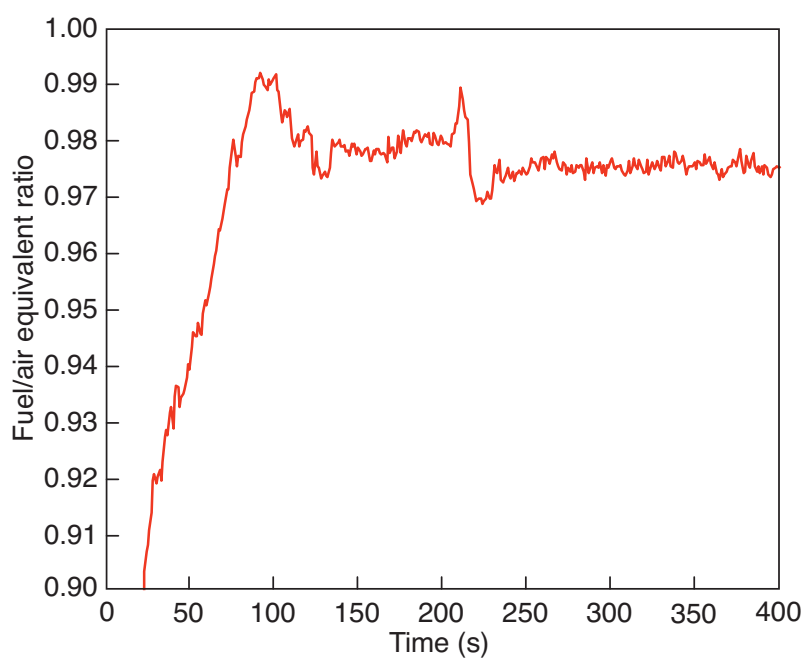

Figure 10

Instantaneous FAER from experimental results @ GSHV = $70000 \mathrm{~h}^{-1}$ and FAER $=0.98$.

\section{FAER variation @ GSHV = $70000 \mathrm{~h}^{-1}$}

A comparison between the experiment and simulation is presented in Figure 8 and Figure 9 for the following operating condition: GSHV $=70000 \mathrm{~h}^{-1}$ and FAER $=0.98$. In this test, simulation behaviour is very correct. $\mathrm{CO}$ and $\mathrm{HC}$ conversion dynamics are coherent with experimental results. Moreover, light-off occurs at identical moments for the experiment and simulation.

This coherent behaviour is confirmed by temperature evolution at the catalyst outlet: experimental and simulation results are quite identical, which means that thermal capacity, heat exchanges between gases, monolith and ambient atmosphere and heat released by reactions are coherent. 

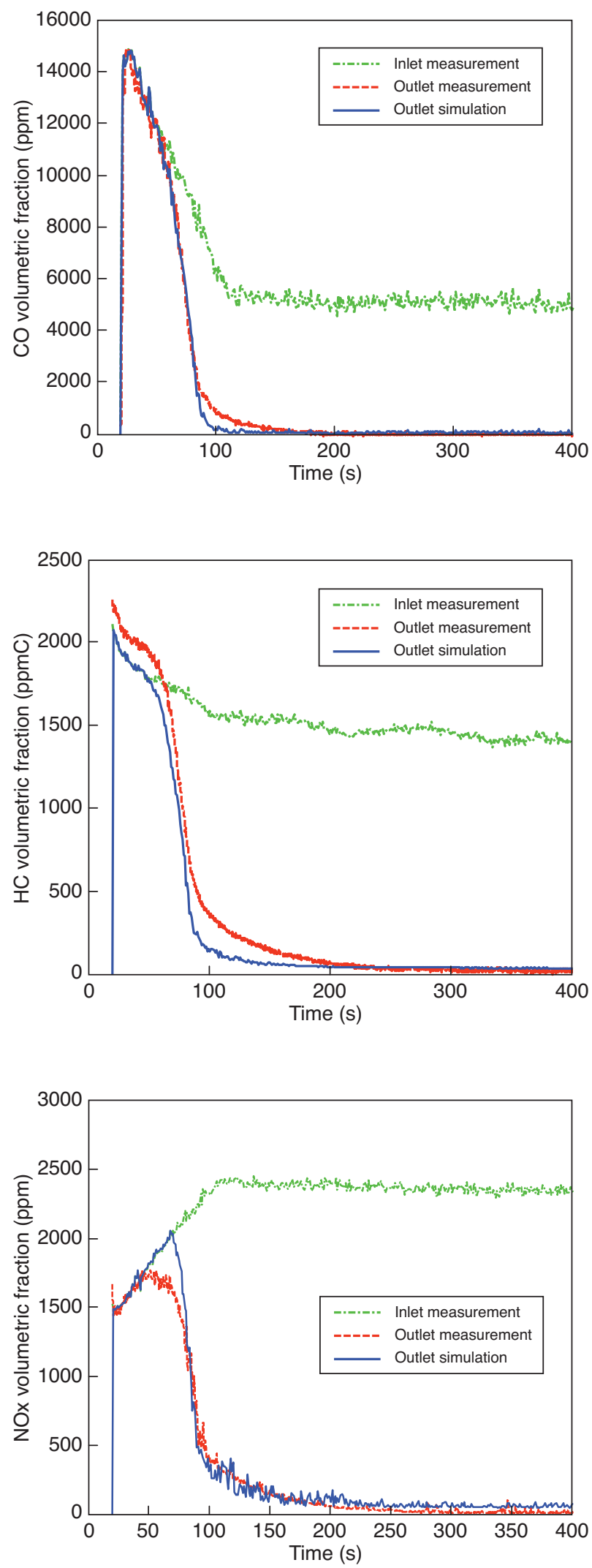

Figure 11

Comparison of pollutant conversion between experimental and simulation results @ GSHV $=70000 \mathrm{~h}^{-1}$ and FAER $=1.00$.

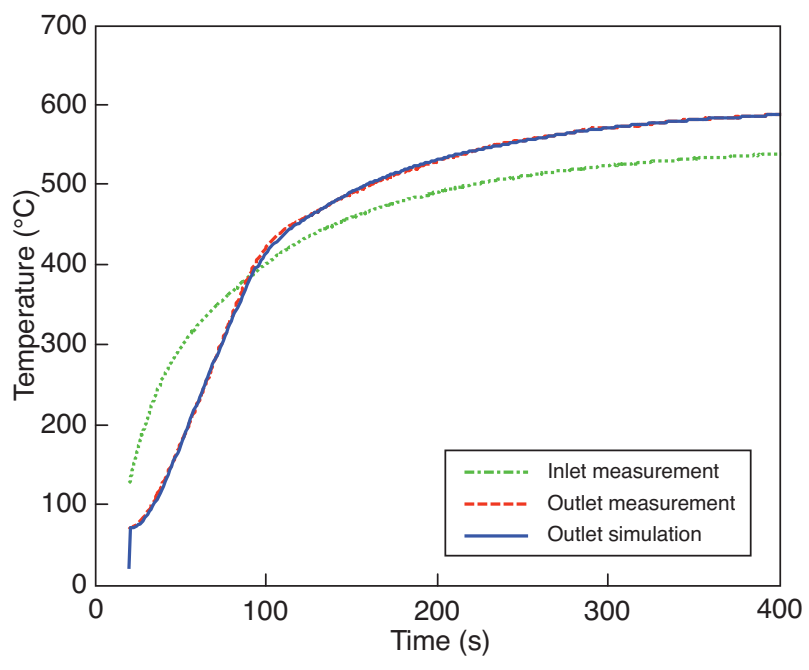

Figure 12

Comparison of temperature evolution between experimental and simulation results @ GSHV $=70000 \mathrm{~h}^{-1}$ and FAER $=1.00$.

Some differences between the experiment and simulation can be noticed in NOx evolution. In the experimental results, NOx conversion occurs when FAR is globally higher than 0.98 (Fig. 10). This conversion also occurs in the simulation but NOx conversion is too sharp in comparison with the experimental results. This shows that the NOx conversion model during lean operating conditions should be improved. The principle of this reaction model is explained in [16]. Future work will consist of improving this model for lean conditions.

Concerning the operating conditions of GSHV $=70000 \mathrm{~h}^{-1}$ and FAER $=1.00$ (Fig. 11 and 12), the results for pollutant conversion and temperature evolution are also very correct for the 3 pollutants $\mathrm{CO}, \mathrm{HC}$ and NOx. For this FAER, pollutant conversions are almost total. These good results are also confirmed by simulation behaviour at a FAER of 1.02 (Fig. 13 and 14).

\section{GSHV variation @ FAER $=1.00$}

From the operating conditions GSHV $=70000 \mathrm{~h}^{-1}$ and FAER $=1.00$ (Fig. 11 and 12), a variation of GSHV was carried out to reduce GSHV to $40000 \mathrm{~h}^{-1}$ (Fig. 15 and 16). In these last operating conditions, temperature increase at the catalyst outlet is slower than in the previous operating conditions at GSHV $=70000 \mathrm{~h}^{-1}$ but the temperature of the beginning of pollutant conversion is globally the same. This phenomenon is well reproduced by the simulation: pollutant conversion occurrence and dynamics are very coherent with experimental results. 

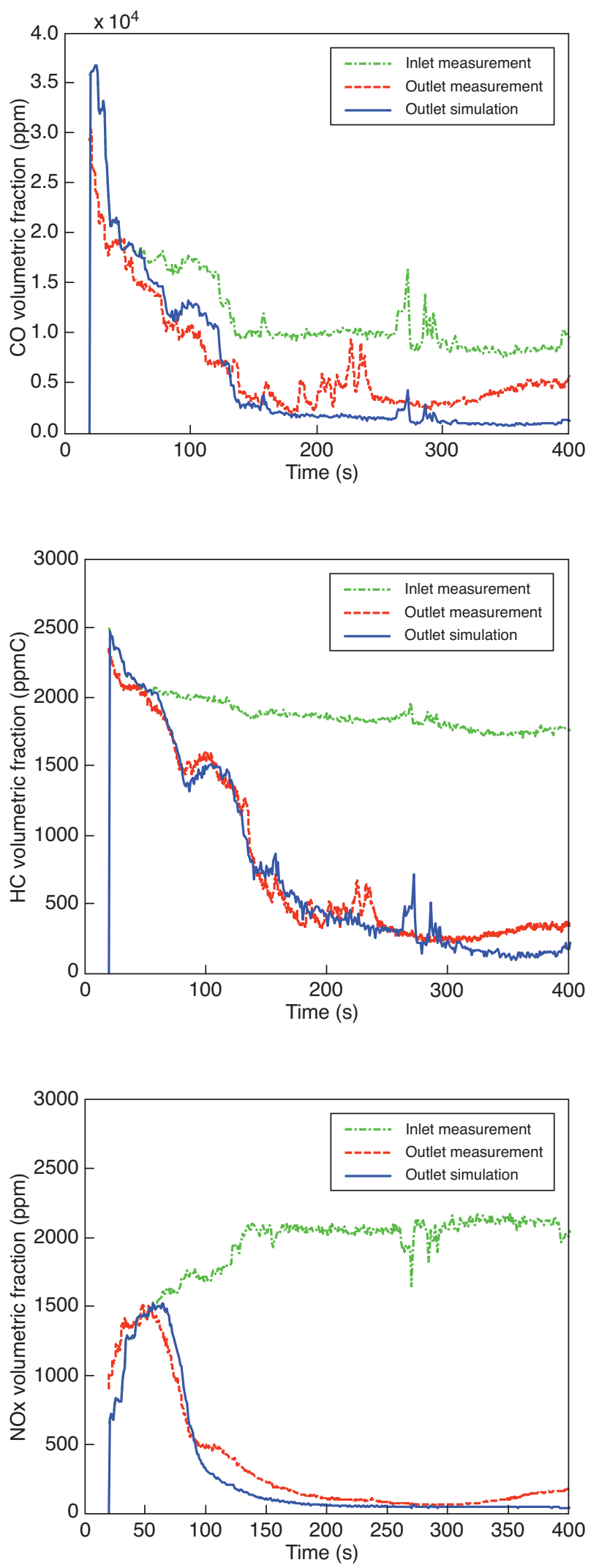

Figure 13

Comparison of pollutant conversion between experimental and simulation results @ GSHV =70000 h-1 and FAER =1.02.

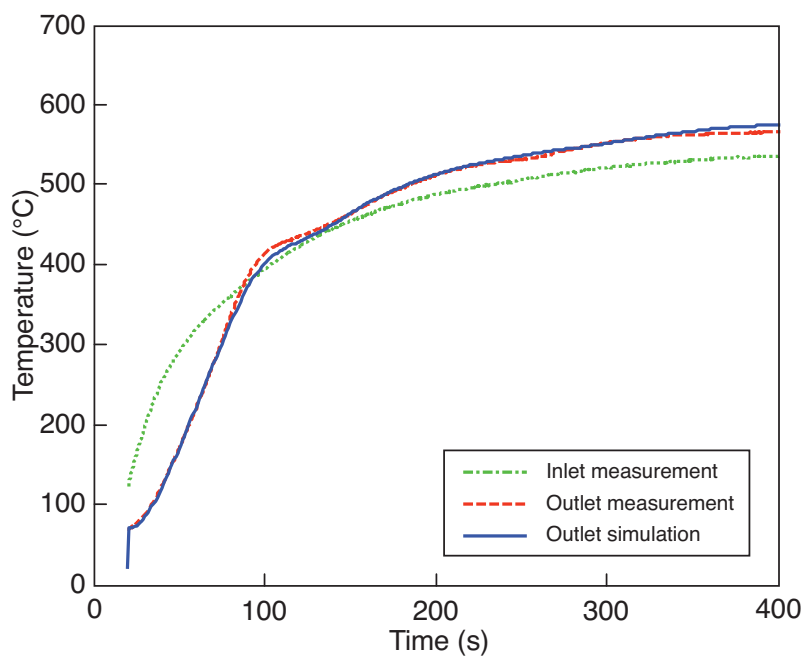

Figure 14

Comparison of temperature evolution between experimental and simulation results @ GSHV $=70000 \mathrm{~h}^{-1}$ and FAER $=1.02$.

\subsection{Conclusion}

As shown previously, simulation results are in good agreement with experimental results for different operating conditions. The 8-reaction scheme allows representing very well a $3 \mathrm{WC}$ behaviour for different fuel-air ratios and temperature dynamics at the catalyst outlet.

\section{DIESEL OXIDATION CATALYST (DOC)}

\subsection{Study Context}

Technologies for exhaust gas after-treatment are different for spark ignition (SI) and compression ignition (CI) engines. Because of the globally lean combustion operating conditions of Diesel engines, 3WC cannot be used for this kind of powertrain. A Diesel oxidation catalyst is used to convert $\mathrm{HC}$ and $\mathrm{CO}$ in lean environments, whereas NOx and soot are treated by SCR or LNT catalysts (see Sect. 6 and 7).

In this part, the development of a DOC simulator is described. The objective is to prove that a $0 \mathrm{D}$ simulator is able to predict $\mathrm{HC}$ and $\mathrm{CO}$ oxidation well, with the associated consequences on downstream gas temperature. Test bench experiments are required to calibrate and validate numerical results.

\subsection{Experimental Setup}

The engine used is a 4-cylinder engine with a 2.2-L cylinder displacement. The exhaust line is composed of a DOC (main characteristics described in Tab. 2) and a DPF. The aim of 


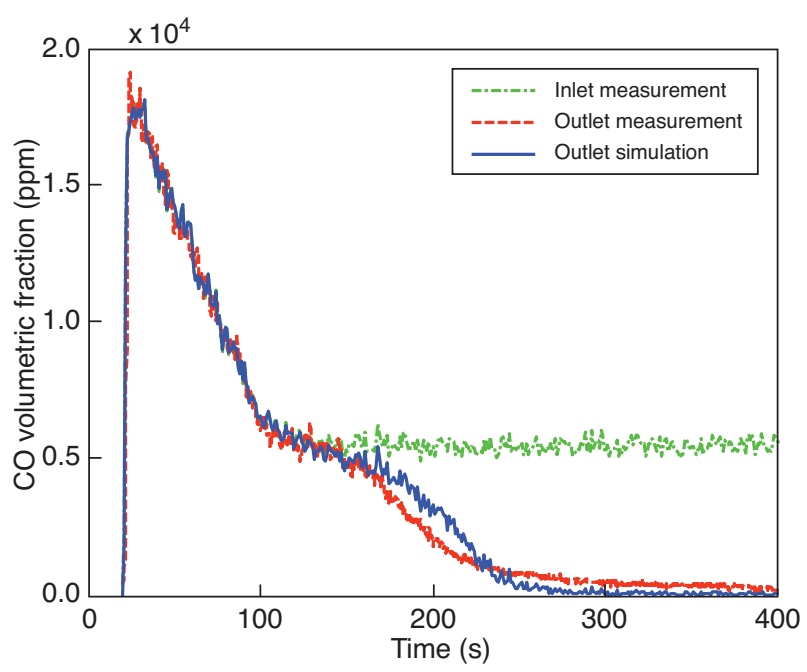

TABLE 2

DOC main characteristics

\begin{tabular}{c|c}
\hline Volume & $0.8 \mathrm{~L}$ \\
\hline Substrate & Cordierite \\
\hline Precious metal load & $110 \mathrm{~g} / \mathrm{ft}^{3}$ \\
\hline
\end{tabular}

experimental tests is to measure gas temperature variations due to heat release by $\mathrm{HC}$ oxidation. Tests consist of performing steps of $\mathrm{HC}$ and measuring the associated gas temperature increase downstream of catalyst.

Experimental measurements for DOC characterisation were the following (Fig. 17):

- exhaust mass flow rate upstream of the catalyst;

- gas temperature upstream and downstream of the catalyst;

- gas composition upstream and downstream of the catalyst.
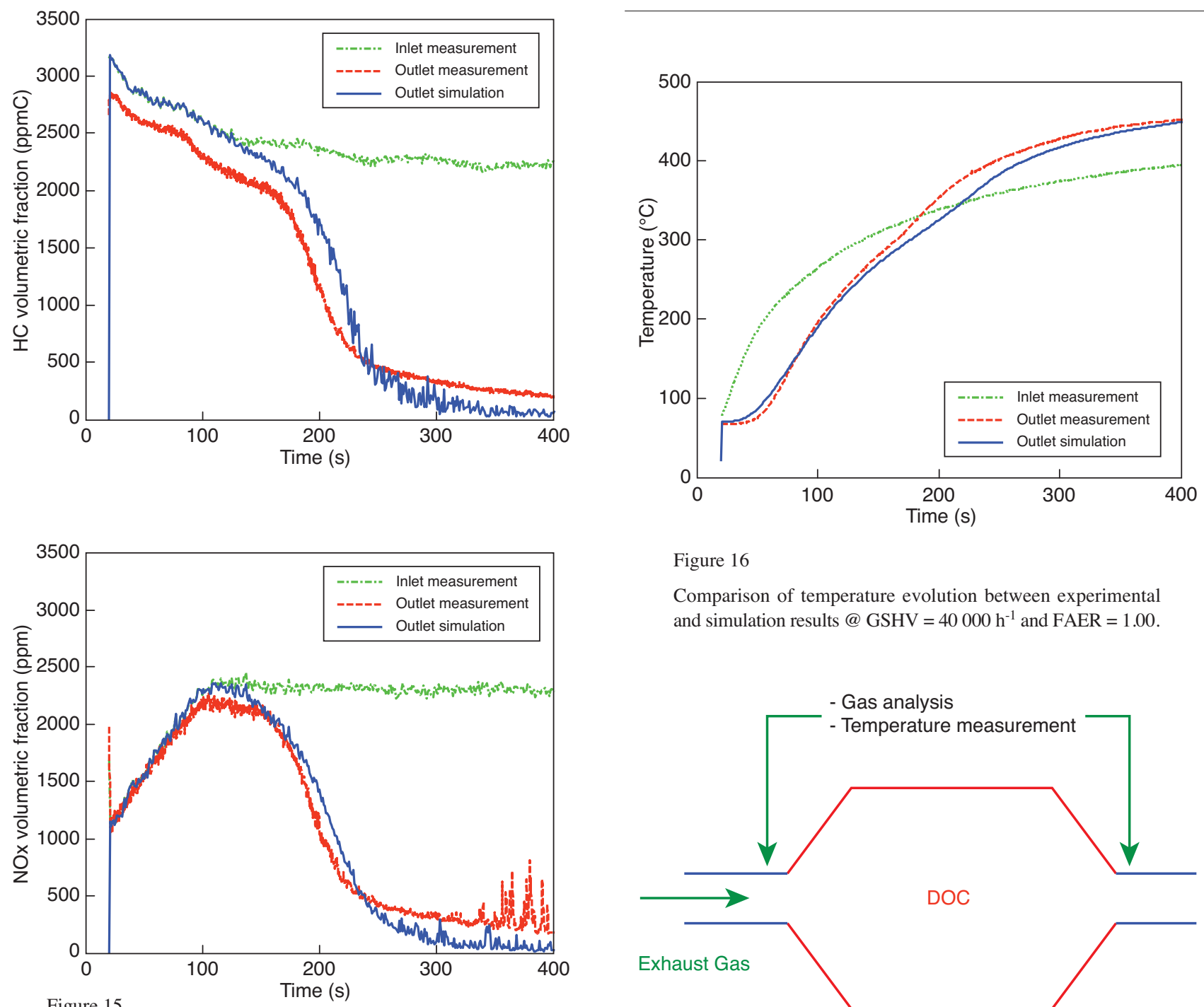

Figure 15

Comparison of pollutant conversion between experimental and simulation results @ GSHV $=40000 \mathrm{~h}^{-1}$ and FAER $=1.00$.

Figure 16

Comparison of temperature evolution between experimental and simulation results @ GSHV = 40000 h-1 and FAER = 1.00.

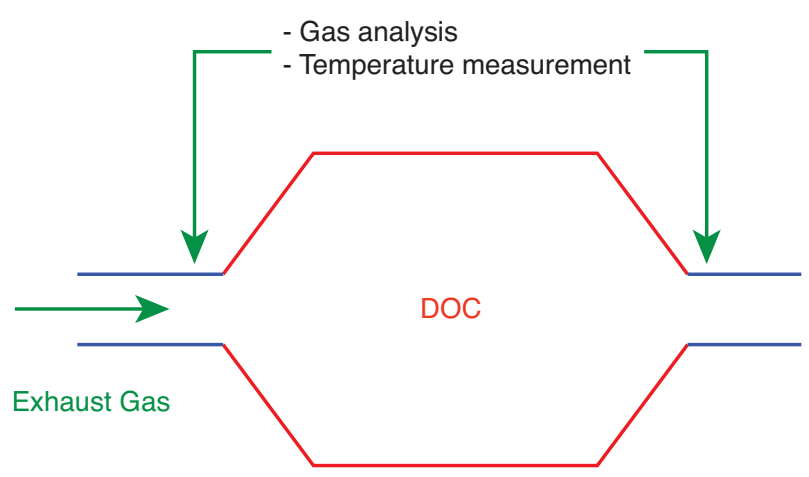

Figure 17

DOC exhaust line configuration. 
Seven steady-state operating conditions were used to calibrate the simulator. They correspond to various loads (IMEP from 0.9 to 5.4 bar) at different engine speeds (from 975 to $3325 \mathrm{rpm}$ ). Table 3 summarises the operating points with associated exhaust mass flow rate and gas temperature upstream the catalyst.

Figure 18 shows the typical tests performed in the different operating conditions. Several steps of $\mathrm{HC}$ quantities are carried out at the DOC inlet. HC conversion (HC quantities downstream of the catalyst are less than $2000 \mathrm{ppm}$ ) generates an increase in DOC outlet temperature. The objectives are to simulate in a coherent way the HC conversion and the associated temperature increase.

TABLE 3

Engine steady-state operating conditions for DOC characterisation

\begin{tabular}{c|c|c|c|c}
\multicolumn{5}{c}{ Engine steady-state operating conditions for DOC characterisation } \\
\hline $\begin{array}{c}\text { Test } \\
\text { number } \\
(\#)\end{array}$ & $\begin{array}{c}\text { Engine } \\
\text { speed } \\
(\mathrm{rpm})\end{array}$ & $\begin{array}{c}\text { Engine } \\
\text { load } \\
(\mathrm{bar})\end{array}$ & $\begin{array}{c}\text { Exhaust } \\
\text { mass flow } \\
\text { rate }(\mathrm{kg} / \mathrm{h})\end{array}$ & $\begin{array}{c}\text { Temperature } \\
\text { upstream the } \\
\text { catalyst }\left({ }^{\circ} \mathrm{C}\right)\end{array}$ \\
\hline 1 & 1500 & 3 & 61 & 565 \\
\hline 2 & 2250 & 5 & 122 & 584 \\
\hline 3 & 1375 & 0.9 & 49 & 437 \\
\hline 4 & 975 & 1.6 & 31 & 310 \\
\hline 5 & 2900 & 4.3 & 205 & 527 \\
\hline 6 & 3325 & 5.4 & 273 & 532 \\
\hline 7 & 1275 & 4.6 & 67 & 459 \\
\hline
\end{tabular}
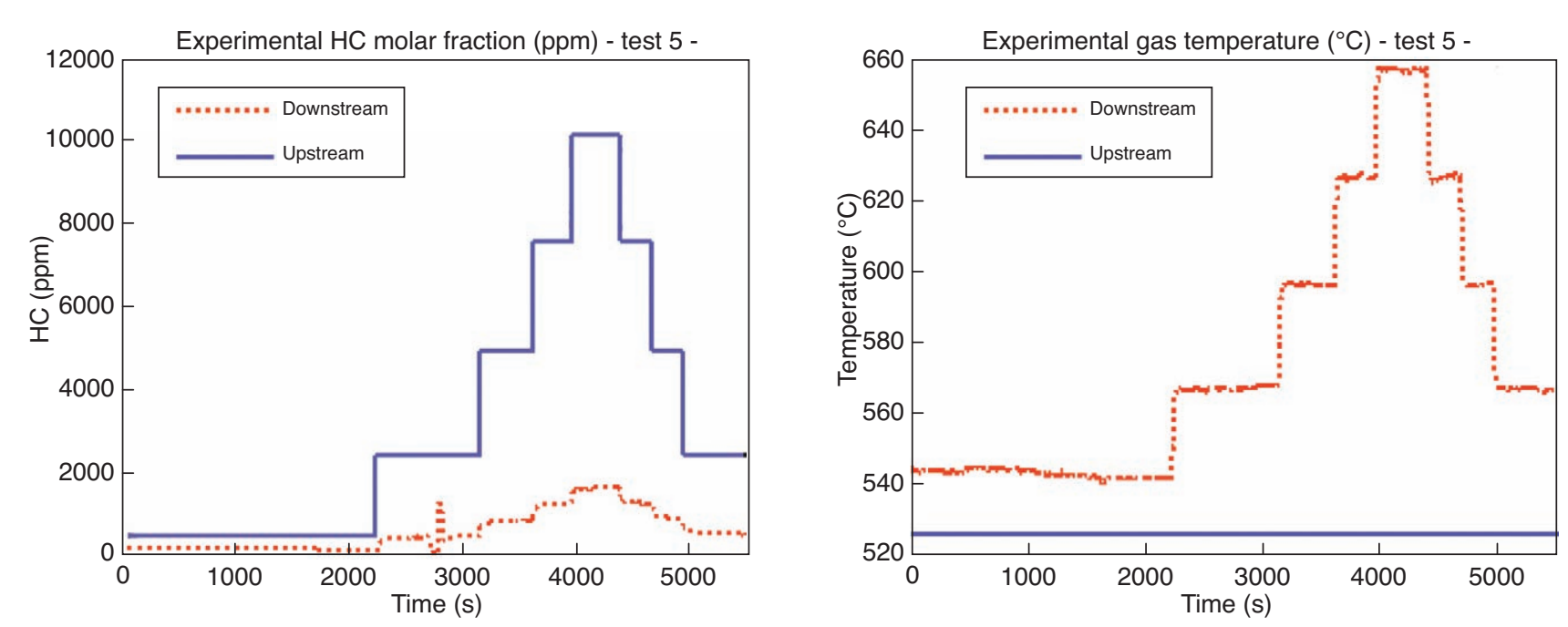

Figure 18

HC molar fraction and gas temperature evolutions upstream and downstream of the catalyst (test \#5).

The main objective consists of predicting $\mathrm{CO}$ and $\mathrm{HC}$ oxidation. This was done by minimising simulation error in comparison with $\mathrm{CO}$ and $\mathrm{HC}$ experimental results measured for each test. The catalyst model is composed of $100 \mathrm{D}$ basic elements representing a good compromise between 1D phenomena (repartition of temperatures and chemical activities through the monolith) and CPU time. The set of parameters used is unique for all tests. This part presents numerical results obtained for test \#3. Moreover, Table 4 summarises the simulation error for each test.

Figure 19 compares numerical and experimental results for test \#3. They illustrate global simulator behaviour:

- gas temperature downstream of the catalyst is close to test bed results. Absolute error is lower than $20^{\circ} \mathrm{C}$. It shows that calculation of heat released by $\mathrm{HC}$ and $\mathrm{CO}$ combustion is coherent; 
- CO and HC oxidation efficiency never reach $100 \%$ due to a small residence time in the catalyst (corresponding to a high GSHV);

- the numerical results show that the DOC model can predict $\mathrm{CO}$ oxidation efficiency. Indeed, absolute error between numerical and experimental results is lower than $0.5 \%$ and global dynamic behaviour is well represented. $\mathrm{CO}$ oxidation efficiency decreases whereas downstream temperature increases. It was interpreted as a consequence of inhibition due to high concentration of HC. The simulation reproduces well this phenomenon noticed in experimental results;

- global HC emissions downstream of the catalyst are also well simulated: absolute error is lower than $1.5 \%$. However, the corresponding relative dynamic behaviour is not correctly reproduced by the OD DOC model. In fact, $\mathrm{HC}$ oxidation efficiency rises with temperature increase, whereas simulated $\mathrm{HC}$ oxidation efficiency decreases. In this case, the effect of temperature increase on the $\mathrm{HC}$ reaction rate seems to be more predominant than the inhibition process. Future work will consist of improving this inhibition process modelling, which is currently described as the Langmuir-Hinshelwood type [17]:

$$
\begin{gathered}
R_{1}=k_{1} \frac{[\mathrm{CO}]\left[\mathrm{O}_{2}\right]}{G} \\
R_{2}=k_{2} \frac{[\mathrm{HC}]\left[\mathrm{O}_{2}\right]}{G} \\
G=T\left(1+k_{a d, 1}[\mathrm{NOx}]^{0.7}\right) \times \\
\left(1+k_{a d, 2}[\mathrm{CO}]^{2}[\mathrm{HC}]^{2}\right) \times \\
\left(1+k_{a d, 3}[\mathrm{CO}]+k_{a d, 4}[\mathrm{HC}]\right)^{2}
\end{gathered}
$$

with $k_{i}=$ kinetic coefficient, $k_{a d, i}=$ absorption coefficient .

Table 4 presents the maximal absolute errors of the simulated $\mathrm{HC}$ and $\mathrm{CO}$ efficiencies in the tests presented in

TABLE 4

$\mathrm{HC}$ and $\mathrm{CO}$ oxidation efficiencies' absolute errors for each test

\begin{tabular}{c|c|c}
\hline & \multicolumn{2}{|c}{ Absolute error (\%) } \\
\hline Test & HC & CO \\
\hline 1 & 3.2 & 0.6 \\
\hline 2 & 5 & 4.6 \\
\hline 3 & 0.5 & 0.6 \\
\hline 4 & 1.1 & 0.9 \\
\hline 5 & 2 & 5.5 \\
\hline 6 & 3.9 & 5.1 \\
\hline 7 & 1.7 & 3.0 \\
\hline
\end{tabular}
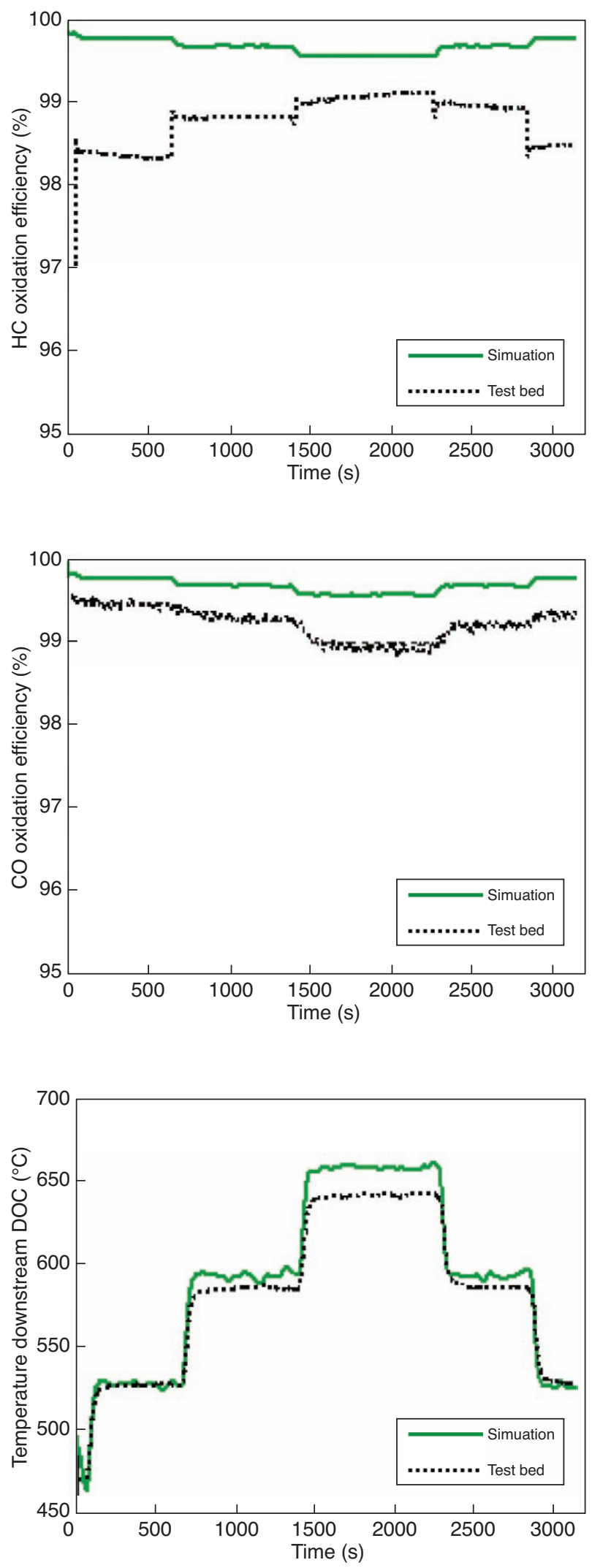

Figure 19

Simulation and experimental results for test No. 3: $\mathrm{HC}, \mathrm{CO}$ and gas temperature downstream of the catalyst. 
Table 3. Simulation results are close to those of the test bed, with an absolute error lower than 6\%. Higher absolute errors on $\mathrm{CO}$ efficiencies are reached for significant mass flow rates of tests 2,5 and 6 . These errors are mainly due to the global diffusion model based on strong assumptions used in the present approach. The HC efficiency errors are probably due to the inhibition model based on a simple Langmuir-Hinshelwood expression.

\subsection{Conclusion}

Even if some differences were underlined, simulation results are in good agreement with experimental results. The accuracy of the resulting simulator is sufficiently high to be used in control applications given that the corresponding CPU time of the simulator is about 80 times faster than real time.

\section{NOX TRAP SYSTEM}

\subsection{Study Context}

Lean-burn engines are one way to reduce $\mathrm{CO}_{2}$ emissions and at the same time improve fuel economy. The drawback is of the difficulty of selectively reducing NOx in an oxygen-rich environment. Two approaches are being developed to answer this challenge. One technology deals with the continuous selective catalytic reduction (SCR) of NOx. It takes advantage of the ability of some catalysts to allow the selective reaction of a limited amount of reducing species with NOx rather than $\mathrm{O}_{2}$ (see Sect. 7). An alternative technology is based on NOx storage and reduction. The overall principle of catalyst operation during this cycle can be described by five reaction steps as summarised by Epling et al. [18]:

- $\mathrm{NO}$ oxidation into $\mathrm{NO}_{2}$

- $\mathrm{NO}$ or $\mathrm{NO}_{2}$ sorption on the surface in the form of nitrites or nitrates;

- Exhaust reducing agent evolution when exhaust gases switch to rich conditions;

- NOx release from nitrite or nitrate sites;

- NOx reduction to $\mathrm{N}_{2}$.

Each of these catalytically activated steps is critical for an efficient operation of the lean NOx trap (LNT).

A OD LNT model was developed to represent the complete cycle of NOx storage and reduction. The simulation results were calibrated and validated with laboratory test results, as presented in this part of the paper.

\subsection{Experimental Setup}

Different tests were performed on a flow reactor such as NOx storage at a given temperature and storage/reduction cycles [19].
LNT sample sizes were $25 \mathrm{~mm}$ in diameter and $50 \mathrm{~mm}$ in length. Gas temperature was measured upstream and downstream of the sample. The gas hourly space velocity was $30000 \mathrm{~h}^{-1}$. Different gas compositions were chosen close to a lean Diesel environment (FAER of 0.3 and 0.6) and to a rich

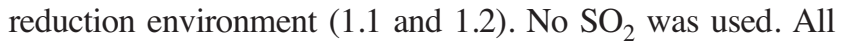
gases were fed to the reactor via mass flow controllers, while water vapour was injected through a vaporiser in a $\mathrm{N}_{2}$ flow. Analysed gases were $\mathrm{CO}_{2}, \mathrm{O}_{2}, \mathrm{CO}, \mathrm{HC}, \mathrm{NOx}, \mathrm{NO}$ and $\mathrm{NO}_{2}$. The effect of sulphur was not investigated in this work.

\subsection{Reaction Scheme}

The reactions considered in the LNT model are those presented for the Diesel oxidation catalyst (see Sect. 5) with the following additional reactions:

- NOx storage (reversible reactions):

$$
\begin{aligned}
& 2 \mathrm{BaCO}_{3}+4 \mathrm{NO}_{2}+\mathrm{O}_{2}=2 \mathrm{Ba}\left(\mathrm{NO}_{3}\right)_{2}+2 \mathrm{CO}_{2} \\
& 2 \mathrm{BaCO}_{3}+4 \mathrm{NO}+\mathrm{O}_{2}=2 \mathrm{Ba}\left(\mathrm{NO}_{2}\right)_{2}+2 \mathrm{CO}_{2}
\end{aligned}
$$

- Stored NOx reduction

$$
\begin{gathered}
\mathrm{Ba}\left(\mathrm{NO}_{3}\right)_{2}+\frac{1}{x} \mathrm{C}_{x} \mathrm{H}_{y}=\mathrm{BaCO}_{3}+2 \mathrm{NO}+\frac{y}{2 x} \mathrm{H}_{2} \mathrm{O} \\
\frac{1}{2} \mathrm{Ba}\left(\mathrm{NO}_{2}\right)_{2}+\frac{1}{4 x+y} \mathrm{C}_{x} \mathrm{H}_{y}+\frac{x+\frac{y}{2}}{4 x+y} \mathrm{CO}_{2}=\frac{1}{2} \mathrm{BaCO}_{3} \\
+\mathrm{NO}+\frac{\frac{y}{2}}{4 x+y} \mathrm{H}_{2} \mathrm{O}
\end{gathered}
$$

The corresponding reaction rates are $\left(\mathrm{mol} / \mathrm{m}^{3} / \mathrm{s}\right)$ :

$$
\begin{aligned}
& R_{1}=k_{1}^{+} \cdot x_{\mathrm{NO}_{2}} \cdot N S C\left(1-\theta_{\mathrm{NO}}-\theta_{\mathrm{NO}_{2}}\right)-k_{1}^{-} N S C \cdot \theta_{\mathrm{NO}_{2}} \\
& R_{2}=k_{2}^{+} \cdot x_{\mathrm{NO}} \cdot x_{\mathrm{O}_{2}}^{0.25} N S C\left(1-\theta_{\mathrm{NO}}-\theta_{\mathrm{NO}_{2}}\right)-k_{2}^{-} N S C \cdot \theta_{\mathrm{NO}} \\
& R_{3}=k_{3} \cdot x_{\mathrm{HC}} \cdot\left(N S C \cdot \theta_{\mathrm{NO}}\right)^{0.5} \\
& R_{4}=k_{4} \cdot x_{\mathrm{HC}} \cdot\left(N S C \cdot \theta_{\mathrm{NO}_{2}}\right)^{0.5}
\end{aligned}
$$

where $x_{i}$ designates the molar fraction of species $i$; NSC, the NOx Storage Capacity of the LNT catalyst $\left(\mathrm{mol} / \mathrm{m}^{3}\right)$ and $\theta$, the coverage rate of storage sites.

Reaction rates were adapted from [20].

\subsection{Simulation Results}

The complete LNT model was composed of 4 OD elements to account for temperature and gas composition evolution through the catalyst. 


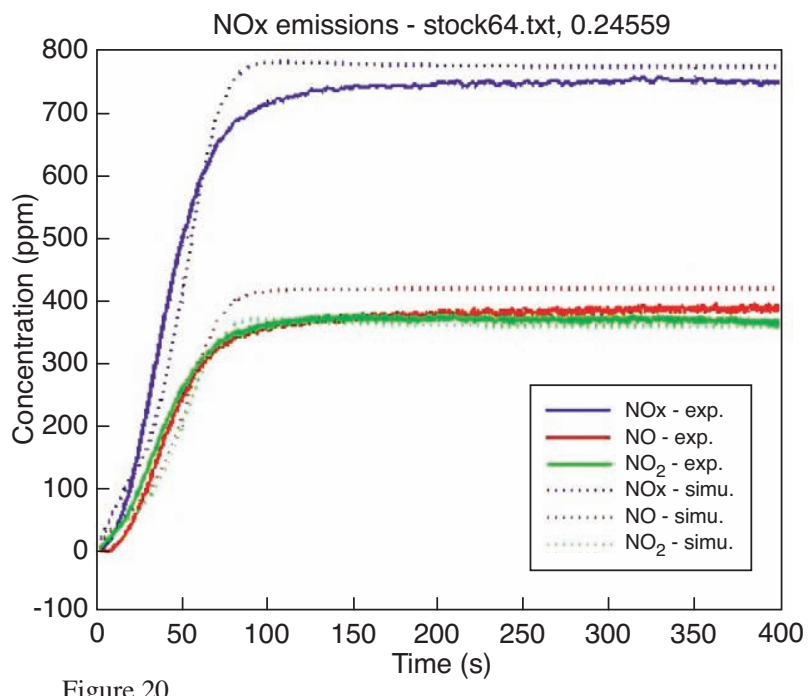

Figure 20

NOx storage at $350^{\circ} \mathrm{C}$, eq. ratio $=0.3$ (extracted from [22]).

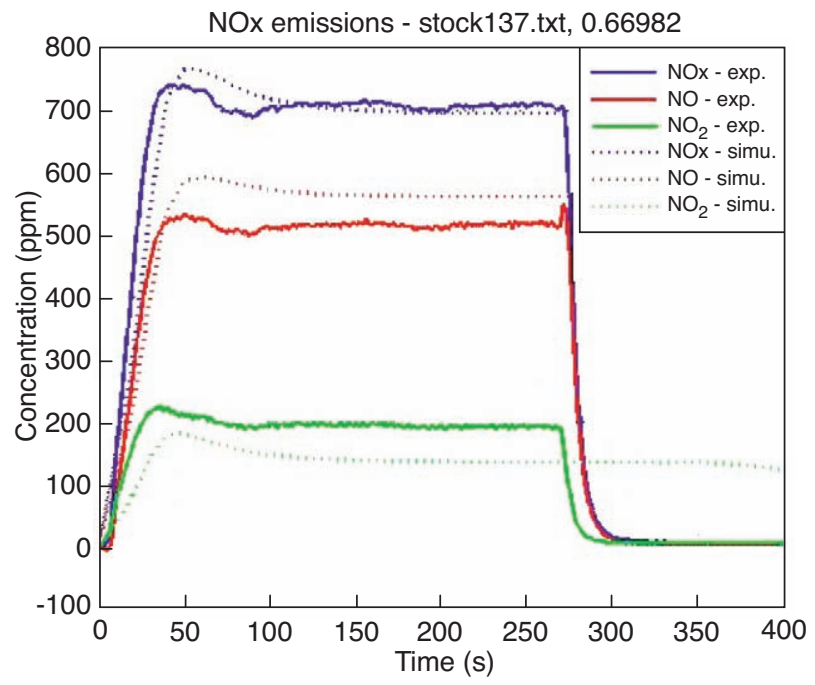

Figure 21

NOx storage at $400{ }^{\circ} \mathrm{C}, \mathrm{FAER}=0.6$ (extracted from [19]).

\section{Simulation of NOx storage}

NOx storage was measured as a function of time in a lean gas mixture at a given temperature. An illustration is displayed in Figure 20: NOx are measured downstream of the LNT at a given temperature of $350^{\circ} \mathrm{C}$ (solid curves). At the beginning of the test, the main part of NOx is stored inside the catalyst. The storage efficiency then decreases as the trap gets saturated.

Dotted curves represent the numerical results obtained with the calibrated model. Another example of the model's ability to predict NOx storage is given in Figure 21 (the end

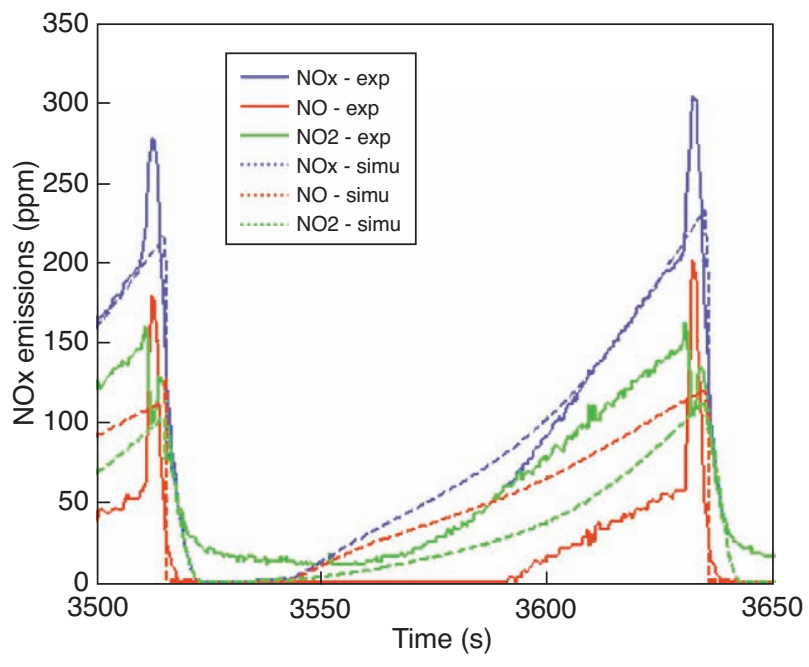

Figure 22

NOx storage and reduction cycles at $350^{\circ} \mathrm{C}$ (LNT inlet temperature). FAER switched between 0.3 and 1.1 (extracted from [19]).

of the storage test after about 270 seconds was not simulated). Temperature is $400^{\circ} \mathrm{C}$. A decrease in the NOx storage capacity is observed because the LNT is less efficient at this high temperature than at $350^{\circ} \mathrm{C}$.

These two graphs show that the simulation is in a good agreement with experimental results both in terms of $\mathrm{NO}_{2}$ formation and $\mathrm{NO} / \mathrm{NO}_{2}$ storage.

Simulation results (dotted curves) obtained for the complete storage/reduction cycle are compared with experimental measurement (solid curves) in Figure 22.

\subsection{Conclusion}

The model proves again to be quite predictive in conditions very close to those encountered by a LNT mounted under a vehicle. Such a LNT model can be used to simulate a complete exhaust system composed of, for instance, DOC and LNT devices or DOC, LNT and DPF systems.

\section{SELECTIVE CATALYTIC REDUCTION (SCR) SYSTEM}

The SCR model presented in this part is the last model developed in the IFP-Exhaust library. As will be seen below, it was created from the literature [21]. At the moment, its validation has been achieved only on synthetic gas bench tests results extracted from the literature [22].

\subsection{Study Context}

Besides the NOx trap system (see Sect. 6), an alternative way to reduce NOx contained in exhaust gases of lean-burn 
engines is the use of a Selective Catalytic Reduction (SCR) catalyst. In this system, NOx emissions are reduced by ammonia $\left(\mathrm{NH}_{3}\right)$. This reducing species comes from a a solution injected upstream of the catalyst called AdBlue ${ }^{\circledR}$ (generally composed of $32.5 \%$ in mass of urea and $67.5 \%$ in mass of water). The NOx reduction mechanism is heterogeneous catalysis reaction: adsorbed $\mathrm{NH}_{3}$ reacts with gaseous $\mathrm{NOx}$. The overall mechanism of such a catalyst can be summarised in four steps:

- Urea injection upstream of the catalyst;

- Urea decomposition into $\mathrm{NH}_{3}$;

- $\mathrm{NH}_{3}$ sorption on the catalyst surface;

- $\mathrm{NH}_{3}$ oxidation by $\mathrm{NOx}$ and eventually $\mathrm{O}_{2}$.

This paper focuses on steps 3 and 4 occurring in the SCR catalyst. A OD model of a SCR catalyst was developed, integrating chemical reactions corresponding with these two steps. Static and dynamic behaviour of this model was both calibrated and validated thanks to data found in the literature [21]. Validation results are described in this part.

\subsection{Reaction Scheme}

Several chemical reactions, desirable or undesirable, occur during the NOx reduction process in a SCR catalyst (Tab. 5 and 6).

TABLE 5

Desirable reactions

\begin{tabular}{l}
$4 \mathrm{NH}_{3(a d)}+4 \mathrm{NO}+\mathrm{O}_{2} \rightarrow 4 \mathrm{~N}_{2}+6 \mathrm{H}_{2} \mathrm{O}$ \\
$4 \mathrm{NH}_{3(a d)}+6 \mathrm{NO} \rightarrow 5 \mathrm{~N}_{2}+6 \mathrm{H}_{2} \mathrm{O}$ \\
$8 \mathrm{NH}_{3(a d)}+6 \mathrm{NO}_{2} \rightarrow 7 \mathrm{~N}_{2}+12 \mathrm{H}_{2} \mathrm{O}$ \\
$4 \mathrm{NH}_{3(a d)}+2 \mathrm{NO}+2 \mathrm{NO}_{2} \rightarrow 4 \mathrm{~N}_{2}+6 \mathrm{H}_{2} \mathrm{O}$ \\
\hline
\end{tabular}

TABLE 6

Undesirable reactions

$$
\begin{aligned}
& 2 \mathrm{NH}_{3(a d)}+8 \mathrm{NO} \rightarrow 5 \mathrm{~N}_{2} \mathrm{O}+3 \mathrm{H}_{2} \mathrm{O} \\
& 4 \mathrm{NH}_{3(a d)}+4 \mathrm{NO}+3 \mathrm{O}_{2} \rightarrow 4 \mathrm{~N}_{2} \mathrm{O}+6 \mathrm{H}_{2} \mathrm{O} \\
& 4 \mathrm{NH}_{3(a d)}+5 \mathrm{O}_{2} \rightarrow 4 \mathrm{NO}+6 \mathrm{H}_{2} \mathrm{O} \\
& 4 \mathrm{NH}_{3(a d)}+7 \mathrm{O}_{2} \rightarrow 4 \mathrm{NO}_{2}+6 \mathrm{H}_{2} \mathrm{O} \\
& 4 \mathrm{NH}_{3(a d)}+4 \mathrm{O}_{2} \rightarrow 2 \mathrm{~N}_{2} \mathrm{O}+6 \mathrm{H}_{2} \mathrm{O} \\
& 4 \mathrm{NH}_{3(a d)}+3 \mathrm{O}_{2} \rightarrow 2 \mathrm{~N}_{2}+6 \mathrm{H}_{2} \mathrm{O}
\end{aligned}
$$

Among all these reactions, only a few were selected to design the SCR catalyst model. Chemical reactions occurring in the absence of $\mathrm{O}_{2}$ and/or NO are dismissed as they do not represent the exhaust gas composition of Diesel engines. Besides, most of the undesirable reactions are not favoured, except the last one for temperatures greater than $400^{\circ} \mathrm{C}$. So, the chemical reactions implemented in the SCR catalyst model are:

- $\mathrm{NH}_{3}$ sorption:

$$
\mathrm{NH}_{3(g)} \rightleftarrows \mathrm{NH}_{3(a d)}
$$

- NOx reduction:

Standard SCR reaction:

$$
4 \mathrm{NH}_{3(a d)}+4 \mathrm{NO}+\mathrm{O}_{2} \rightarrow 4 \mathrm{~N}_{2}+6 \mathrm{H}_{2} \mathrm{O}
$$

Fast SCR reaction:

$$
\begin{gathered}
\quad 4 \mathrm{NH}_{3(a d)}+2 \mathrm{NO}+2 \mathrm{NO}_{2} \rightarrow 4 \mathrm{~N}_{2}+6 \mathrm{H}_{2} \mathrm{O} \\
-\mathrm{O}_{2} \text { reduction } \\
4 \mathrm{NH}_{3(a d)}+3 \mathrm{O}_{2} \rightarrow 2 \mathrm{~N}_{2}+6 \mathrm{H}_{2} \mathrm{O}
\end{gathered}
$$

With corresponding reaction rates:

$$
\begin{gathered}
R_{1}=k_{1}^{+} \cdot\left[\mathrm{NH}_{3}\right] \cdot\left(\Omega_{\max }-\Omega_{\mathrm{NH}_{3}}\right)-k_{1}^{-} \cdot\left[\mathrm{NH}_{3}\right] \cdot \Omega_{\mathrm{NH}_{3}} \\
R_{2}=k_{2} \cdot[\mathrm{NO}] \cdot \Omega_{\mathrm{NH}_{3}} \\
R_{3}=k_{3} \cdot[\mathrm{NO}] \cdot\left[\mathrm{NO}_{2}\right] \cdot \Omega_{\mathrm{NH}_{3}} \\
R_{4}=k_{4} \cdot \Omega_{\mathrm{NH}_{3}}
\end{gathered}
$$

where $\Omega_{\max }$ is the maximum amount of $\mathrm{NH}_{3}$ that can be adsorbed and $\Omega_{\mathrm{NH}_{3}}$ is the amount of adsorbed $\mathrm{NH}_{3}$.

\subsection{Static Validation}

The aim here is to assess the performance of the model for various temperatures and $\mathrm{NO} / \mathrm{NO}_{2}$ ratios. This validation is based on experimental results obtained by [22].

\subsubsection{Experimental Setup}

The reactor is a quartz tube filled with $160 \mathrm{mg}$ of powder made out of a commercial $\mathrm{V}_{2} \mathrm{O}_{5}-\mathrm{WO}_{3} / \mathrm{TiO}_{2}$ catalyst. The reaction temperature is measured and controlled by means of a thermocouple. $\mathrm{He}, \mathrm{NO}, \mathrm{NO}_{2}, \mathrm{O}_{2}$ and $\mathrm{NH}_{3}$ feeds are measured and controlled by mass flow controllers. Analysed gases are $\mathrm{NO}, \mathrm{NO}_{2}, \mathrm{NH}_{3}, \mathrm{~N}_{2}$ and $\mathrm{N}_{2} \mathrm{O}$.

\subsubsection{Simulation Results}

The methodology consists of first feeding the reactor with $\mathrm{NH}_{3}$ until an equilibrium in adsorption is reached, and then injecting a step of $\mathrm{NO}$ and/or $\mathrm{NO}_{2}$ (Fig. 23). Gas composition measurements are performed when steady- state conditions are reached. For each $\mathrm{NO} / \mathrm{NO}_{2}$ ratio, various temperatures are tested.

The reactor is modelled by six 0D elements, in order to resolve $1 \mathrm{D}$ phenomena (temperature and gas composition).

The experimental Gas Space Hourly Velocity (GSHV) is $10000 \mathrm{~h}^{-1}$ and is constant for all tests described in this part.

The accuracy of the standard SCR model is first tested. In this test, only NO is fed to the reactor at various temperatures. The efficiency of standard SCR increases with temperature. 


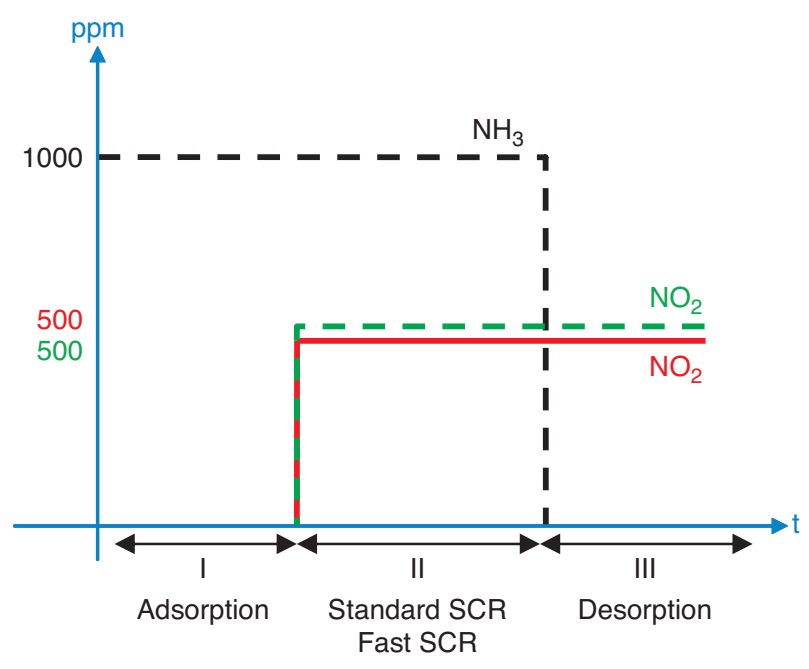

Figure 23

Example of gas composition evolution upstream of the reactor.

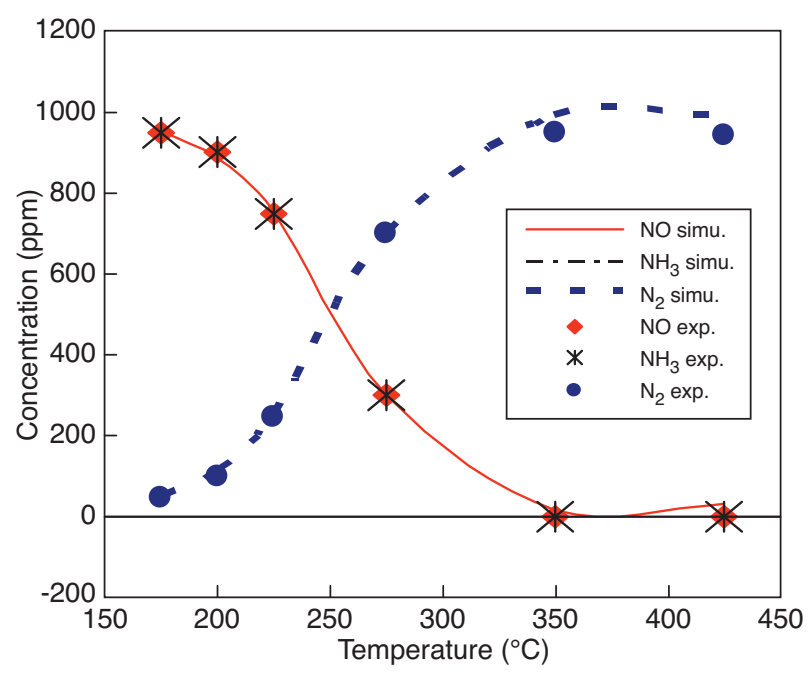

Figure 24

Temperature dependence of $\mathrm{NO}$ reduction for $\mathrm{NO} / \mathrm{NO}_{2}=1 / 0$ (experimental results extracted from [22]).

Simulation results show good agreement with experimental results (Fig. 24) as far as trends and levels are concerned.

The fast SCR is also assessed. The reactor is fed with a $\mathrm{NO} / \mathrm{NO}_{2}$ ratio of $3 / 1$. The presence of $\mathrm{NO}_{2}$ thus enables the fast SCR reaction. For this test, experimental and simulation results are also in good agreement (Fig. 25) except for low temperatures $\left(<200^{\circ} \mathrm{C}\right)$.

In the two previous experiments, the $\mathrm{NO}_{2}$-SCR reaction appears not to occur as the $\mathrm{NO} / \mathrm{NO}_{2}$ ratios are greater than 1 . When this $\mathrm{NO} / \mathrm{NO}_{2}$ ratio is equal to 1 , the simulation results are not as accurate at high temperature (Fig. 26). Indeed, the

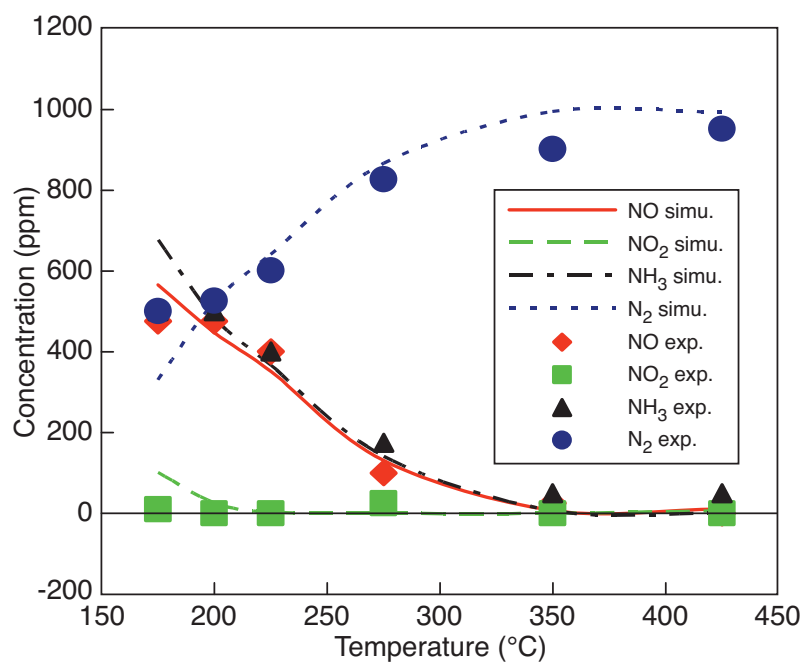

Figure 25

Temperature dependence of $\mathrm{NO}$ and $\mathrm{NO}_{2}$ reduction for $\mathrm{NO} /$ $\mathrm{NO}_{2}=3 / 1$ (experimental results extracted from [22]).

$\mathrm{NO}_{2}$ concentration is overestimated in the simulation, as there is no $\mathrm{NO}_{2}-\mathrm{SCR}$ reaction to consume it.

\subsection{Dynamic Validation}

This validation only concerns the $\mathrm{NH}_{3}$ sorption. Experimental results have been extracted from [21].

\subsubsection{Experimental Setup}

Experimental configuration is identical to static validation, except for the gas hourly space velocity which is: $1.4 \times 10^{5} \mathrm{~h}^{-1}$.

\subsubsection{Simulation Results}

The experiment consists of feeding the reactor with $\mathrm{He}+\mathrm{NH}_{3}$. $\mathrm{NH}_{3}$ concentration is null at the beginning, then increases, enabling $\mathrm{NH}_{3}$ adsorption, is stabilised, and then decreases to zero, causing $\mathrm{NH}_{3}$ desorption (Fig. 27). In the experimental results two phenomena appear:

- the existence of a latency time at the beginning of adsorption;

- a certain inertia at the end of desorption, as desorption continues while there is no more $\mathrm{NH}_{3}$ at the inlet of the catalyst.

The results obtained with simulation are represented in Figure 28. Latency time and desorption inertia are quite well reproduced by the model, as well as $\mathrm{NH}_{3}$ oxidation dependence on temperature.

\subsection{Conclusion}

The first results obtained with the 0D model of the SCR catalyst are very close to experimental ones, both for static and dynamic tests (currently only on synthetic gas bench tests). To be validated with engine test bench results, this 


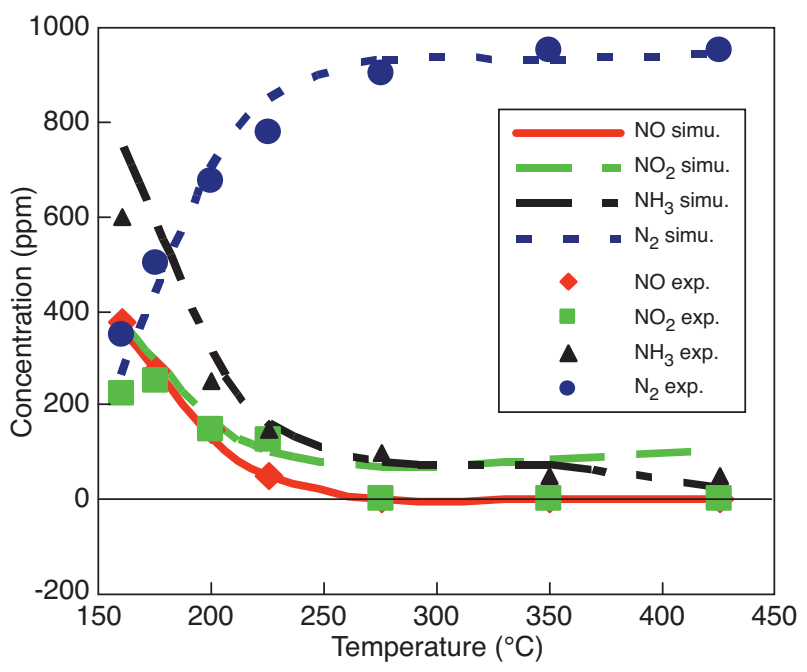

Figure 26

Temperature dependence of $\mathrm{NO}$ and $\mathrm{NO}_{2}$ reduction for $\mathrm{NO} / \mathrm{NO}_{2}=1 / 1$ (experimental results extracted from [22]).

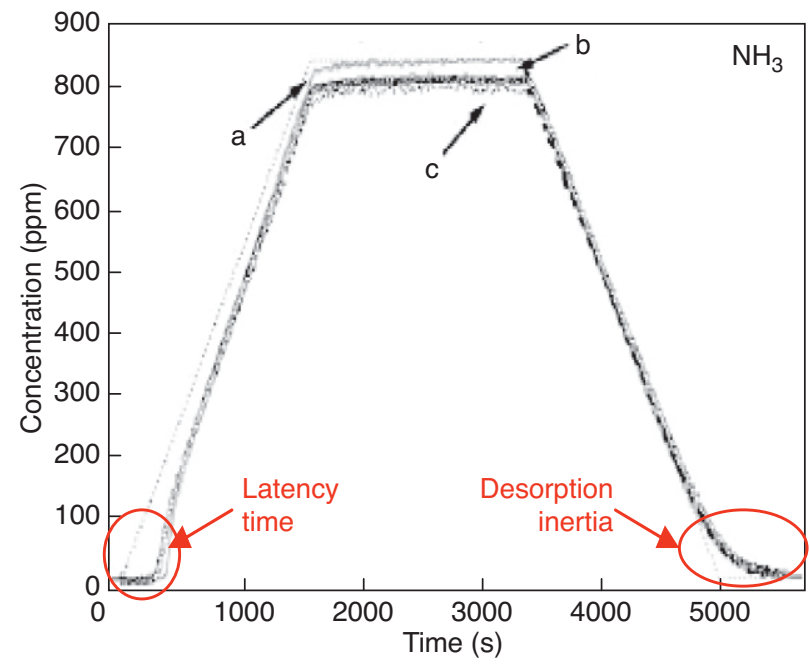

Figure 27

Adsorption/desorption dynamic behaviour of the reactor, for various temperatures: a: $613 \mathrm{~K}$, b: $653 \mathrm{~K}$, c: $673 \mathrm{~K}$ (extracted from [21]). model first has to be improved to take into account the $\mathrm{NO}_{2}$-SCR reaction, for example. This work is currently being performed at IFP.

This model will eventually be used to develop control strategies for urea injection and to simulate vehicle emissions when coupled with an engine model.

\section{DIESEL PARTICULATE FILTER (DPF)}

Nowadays, a Diesel particulate filter is essential in Diesel applications in order to reach the latest emission standards concerning particulates (see Sect. 1). To set up such a solution, simulation tools are particularly useful. In fact, during engine operating conditions, particulates are trapped in the DPF. This soot trapping increases the exhaust line pressure drop. This pressure drop is often used by a control engineer to manage regeneration phases which are necessary to keep a high efficiency of soot trapping and limit engine consumption. To be helpful, the DPF model has to be able to predict precisely the loading phase efficiency and the corresponding pressure drop.

\subsection{Soot Loading and Soot Oxidation}

The soot loading efficiency is supposed to be constant in the model:

$$
m_{\text {soot }}^{\text {stored }}=\chi \cdot \int \dot{m}_{\text {soot }} \cdot d t
$$

$m_{\text {soot }}^{\text {stored }}, m_{\text {soot }}$ corresponds, respectively, to the mass of soot stored in the DPF and the soot mass flow rate of soot in the exhaust gases. $\chi$ is the efficiency of soot loading.

Concerning the soot regeneration, two basic reactions are considered in the model. Soot is modelled as carbon

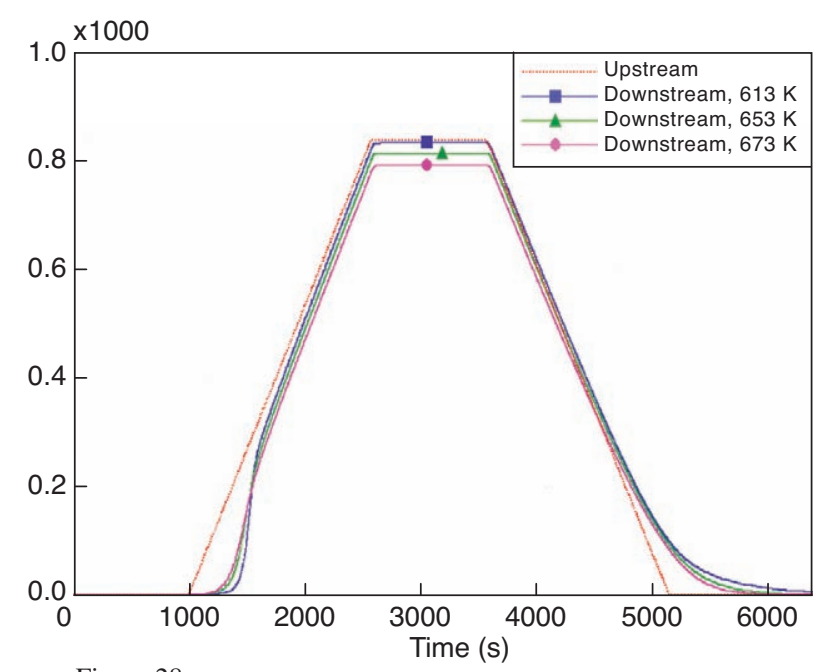

Figure 28

Adsorption/Desorption dynamic behaviour of the model. $\mathrm{NH}_{3}$ upstream and downstream concentrations for various temperatures.

molecules. The first reaction corresponds to the active regeneration [23]:

$$
C_{s}+\left(1-\frac{f_{\mathrm{CO}}}{2}\right) \mathrm{O}_{2} \rightarrow f_{\mathrm{CO}} \mathrm{CO}+\left(1-f_{\mathrm{CO}}\right) \mathrm{CO}_{2}
$$

The second reaction corresponds to the passive regeneration [23]:

$C_{s}+\left(2-g_{\mathrm{CO}}\right) \mathrm{NO}_{2} \rightarrow g_{\mathrm{CO}} \mathrm{CO}+\left(1-g_{\mathrm{CO}}\right) \mathrm{CO}_{2}+\left(2-g_{\mathrm{CO}}\right) \mathrm{NO}$

$f_{\mathrm{CO}}, g_{\mathrm{CO}}$ are, respectively, the $\mathrm{CO}$ selectivity for carbon oxidation by $\mathrm{O}_{2}$ and by $\mathrm{NO}_{2}$. 


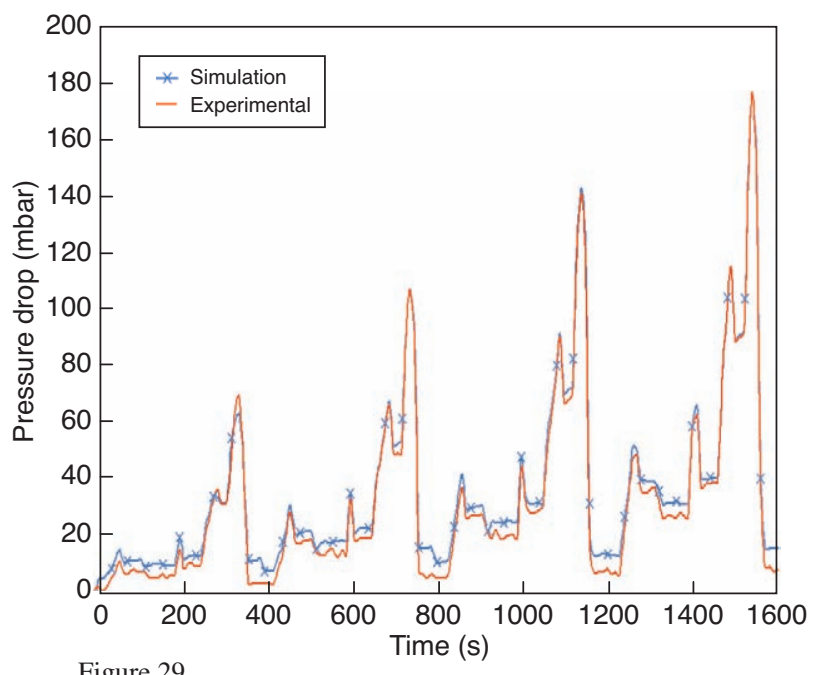

Figure 29

Pressure drop during loading: experimental and numerical results (extracted from [24]).

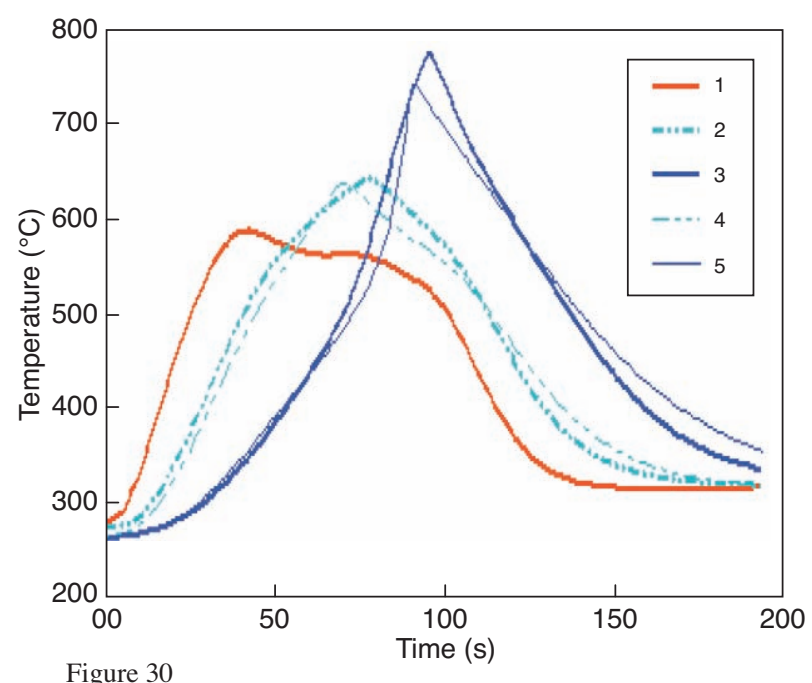

Figure 30

Regeneration propagation along DPF. 1: upstream temperature, 2 and 4 : exp. \& sim. temperature $2 \mathrm{~cm}$ behind the front face, 3 and 5: exp. \& sim. temperature at mid-length (extracted from [24]).

The pressure drop through the porous wall (between the inlet and the outlet channel) is computed from a classical Darcy law [22].

It is also possible to add oxidation kinetics (5.3) to the model in order to simulate a catalysed particulate filter.

\subsection{Simulation Results}

Figure 29 presents the evolution of pressure drop due to the DPF loading measured during four successive EUDC cycles. Mean pressure drop per cycle increases due to soot loading. Simulations show a good agreement with experimental results.

Concerning the DPF regeneration, Figure 30 is a thermal

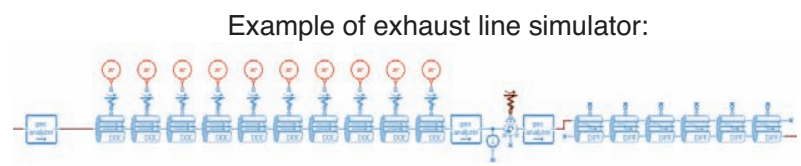

Figure 31

Sketch of DOC +DPF simulator [25].

illustration (temperature evolution) of soot regeneration along the DPF axis at 3 different positions. After 90 seconds, temperature at the mid-length of the DPF is higher than the inlet temperature due to the exothermic soot oxidation. This result illustrates 0D simulation's potential to reproduce one-dimensional phenomena.

To conclude, Figure 31 presents a simulator of an exhaust line composed of a DOC and a DPF which has been used to develop control strategy [25] of the DPF regeneration. In order to be accurate, the DPF model is composed of 6 blocks, whereas the DOC model is composed of 10 blocks. The corresponding CPU time is dependent on the operating conditions. During a transient test (a DPF regeneration, for example), the CPU time remains faster than real time.

\subsection{Conclusion}

In spite of the intrinsic high complexity of a Diesel Particulate Filter, the basic model proposed in this part is adequate for use in a first-order exhaust line simulator. For example, this tool can be very useful to test regeneration strategies designed by a control engineer.

\section{CONCLUSION}

Drastic evolutions of pollutant emissions are changing the challenges concerning research on powertrains. It is now impossible to comply with future regulations only with engine evolutions. Improvements in the air-loop system (for instance, double turbocharger architecture, low-pressure EGR loop) and fuel-loop system (for instance, increase in injection pressure and number of injections) will not offer sufficient gain in terms of raw emissions to be compatible with future emission standards. After-treatment systems are already mandatory (3WC for gasoline engines and DPF for Diesel engines) but after-treatment architecture will be more and more complex with a succession of catalysts to treat separately the different pollutants: $\mathrm{HC}$ and $\mathrm{CO}$ in the DOC, $\mathrm{NOx}$ in the LNT or SCR system, and soot in the DPF.

As seen a few years before with the engine, this increase in system complexity has caused the emergence of two technical fields essential for optimising the system:

- control design to benefit from all the potential of the system;

- system simulation to define the best architecture and help the design of control strategies. 
In this context, 0D modelling seems to be a relevant approach to deal with all these issues. This paper shows the main assumptions and physical phenomena taken into account in this approach. It allows the simulation of all the components used in a modern after-treatment line with very interesting CPU time. This approach permits the creation of different kinds of models: very detailed for understanding and architecture definition, or simpler and dedicated to fast CPU time duration to be compatible with control design constraints. In the always more competitive automotive world, OD modelling dedicated to after-treatment issues seems to be a relevant approach to reduce costs.

\section{ACKNOWLEDGMENTS}

We would like to acknowledge Yann Creff, Ali Otmane, Raphael Lorette, Antoine Albrecht, Pascal Menegazzi, Arnaud Frobert and Stephane Zinola for supporting this work.

\section{REFERENCES}

1 Karnopp D.C., Margolis D.L., Rosenberg R.C. (1990) Systems dynamics: a unified approach, Second Edition, John Wiley \& Sons, New-York.

2 Koltsakis G.C., Konstandinis P.A., Stamatelos A.M. (1997) Development and application range of mathematical models for 3-way catalytic converters, Appl. Catal. B: Environ. 12, 161-191.

3 Depcik C., Assanis D. (2003) One-dimensional automotive catalyst modeling, Prog. Energ. Combust. 31, 308-369.

4 Xu L., Graham G., Mc Cabe R., Hoard J., Yang J. (2008) The Feasibility of an Alumina-Based Lean NOx Trap (LNT) for Diesel and HCCI Applications, SAE 2008-01-0451.

5 Kim Y., Sun J., Kolmanovsky I., Koncsol J. (2003) A phenomenological control oriented lean nox trap model, SAE 2003-011164.

6 Zheng H., Keith J.M. (2007) Averaging Theory for Diesel Particulate Filter Regeneration, AIChe 53, 5.

7 Schär C.M., Onder C.H., Geering H.P. (2004) Control-oriented model of an SCR catalytic converter system, SAE 2004-01-0153.

8 Wurzenberger J.C., Peters B. (2003) Catalytic converters in a 1D cycle simulation code considering 3D behaviour, SAE 2003-01-1002.

9 Onorati A., Ferrari G., D'Errico G., Montenegro G. (2002) The prediction of $1 \mathrm{D}$ unsteady flows in the exhaust system of a S.I. engine including chemical reactions in the gas and solid phase, SAE 2002-01-0003.

10 Tang W., Wahiduzzaman S., Wenzel S., Leonard A., Morel T. (2008) Development of a Quasi-Steady-Approach-Based Simulation Tool for System-Level Exhaust Aftertreatment Modelling, SAE 2008-01-0866.
11 Güthenke A., Chatterjee D., Weibel M., Krutzsh B., Koci P., Marek M., Nova I., Tronconi E. (2008) Current status of modeling lean exhaust gas aftertreatment catalysts, Adv. Chem. Eng. 33, 103-211.

12 Wanker R., Granter H., Bachler G., Rabenstein G., Ennemoser A., Tatschl R., Bollig M. (2002) New physical and chemicals models for the CFD simulation of exhaust gas lines: a generic approach, SAE 2002-01-0066.

13 Peters B.J., Wanker R.J., Münzer A., Wurzenberger J.C. (2004) Integrated $1 \mathrm{D}$ to $3 \mathrm{D}$ simulation workflow of exhaust aftertreatment devices, SAE 2004-01-1132.

14 Konstandopoulos A.G., Kostoglou M., Housiada P., Vlachos N., Zarvalis D. (2003) Multichannel simulation of soot oxidation in diesel particulate filters, SAE 2003-01-0839.

15 Wurzenberger J.C., Wanker R. (2005) Multi-scale SCR Modelling, 1D Kinetic Analysis and 3D System Simulation, SAE 2005-01-0948.

16 Millet C.N., Benramdhane S. (2008) A 3WCC Global Kinetic Model: A Calibration Method Using Laboratory Scale and Engine Test Bench Experiments, SAE 2008-01-0453.

17 Voltz S., Morgan C., Liederman D., Jacob S. (1973) Kinetic Study of Carbon Monoxide and Propylene Oxidation on Platinum Catalysts, Ind. Eng. Chem. Prod. Res. Dev. 12, 294.

18 Epling W.S., Campbell L.E., Yezeretz A., Currier N.W., Parks II J.E. (2004) Overview of the Fundamental Reactions and Degradation Mechanisms of NOx Storage/Reduction Catalysts, Catal.Rev. 46, 163-245.

19 Chedotal R. (2007) Modélisation du catalyseur 4 voies, $P h D$ Thesis, Pierre \& Marie Curie University, 2007

20 Olsson L., Blint R.J., Fridell E. (2005) Global Kinetic Model for Lean NOx Traps, Ind. Eng. Chem. Res. 44, 3021-3032.

21 Nova I., Lietti L., Tronconi E., Forzatti P. (2000) Dynamics of SCR reaction over a $\mathrm{TiO}_{2}$-supported vanadia-tungsta commercial catalyst, Catal. Today 60, 73-82.

22 Ciardelli C., Nova I., Tronconi E., Chatterjee D., Bandl-Konrad B., Weibel M., Krutzsch B. (2007) Reactivity of $\mathrm{NO} / \mathrm{NO}_{2}-\mathrm{NH}_{3}$ SCR system for Diesel exhaust aftertreatment: Identification of the raction network as a function of temperature and $\mathrm{NO}_{2}$ feed content, Appl. Catal. B: Environ. 70, 80-90.

23 Konstandopoulos A.G., Kostoglou M., Skaperdas E., Papaionnou E., Zarvalis D., Kladopoulou E. (2000) Fundamental studies of diesel particulate filters: Transient loading, regeneration and aging, SAE 2000-01-1016.

24 Menegazzi P., Albrecht A., Millet C.N., Aubret P., Thomas V. (2006) A Simulation Tool for Vehicle Emissions, Consumption and Performance Analysis Applications to DPF Modelling and DID Turbocharger Engine Control Design, SAE 2006-01-3004.

25 Mauviot G., Le Berr F., Creff Y., Perretti F., Albrecht A. (2008) A virtual DOC-DPF after-treatment system for control design, Proc. of Diesel Engine After Treatment Conference of SIA, Paris.

26 Lepreux O., Creff Y., Petit N. (2008) Motion Planning for a Diesel Oxidation Catalyst Outlet Temperature, Proc. of the American Control Conference 2008, Seattle, USA.

Final manuscript received in November 2008 Published online in May 2009 or distributed for profit or commercial advantage and that copies bear this notice and the full citation on the first page. Copyrights for components of this work owned by others than IFP must be honored. Abstracting with credit is permitted. To copy otherwise, to republish, to post on servers, or to redistribute to lists, requires prior specific permission and/or a fee: Request permission from Documentation, Institut français du pétrole, fax +33147527078 , or revueogst@ifp.fr. 